\title{
A place of greater safety, Bespiegelingen over een Europees Statuut voor de strafrechtadvocaat
}

Citation for published version (APA):

Spronken, T. N. B. M. (2003). A place of greater safety, Bespiegelingen over een Europees Statuut voor de strafrechtadvocaat. Kluwer. https://doi.org/10.26481/spe.20031010ts

Document status and date:

Published: 10/10/2003

DOI:

$10.26481 /$ spe.20031010ts

Document Version:

Publisher's PDF, also known as Version of record

\section{Please check the document version of this publication:}

- A submitted manuscript is the version of the article upon submission and before peer-review. There can be important differences between the submitted version and the official published version of record.

People interested in the research are advised to contact the author for the final version of the publication, or visit the DOI to the publisher's website.

- The final author version and the galley proof are versions of the publication after peer review.

- The final published version features the final layout of the paper including the volume, issue and page numbers.

Link to publication

\footnotetext{
General rights rights.

- You may freely distribute the URL identifying the publication in the public portal. please follow below link for the End User Agreement:

www.umlib.nl/taverne-license

Take down policy

If you believe that this document breaches copyright please contact us at:

repository@maastrichtuniversity.nl

providing details and we will investigate your claim.
}

Copyright and moral rights for the publications made accessible in the public portal are retained by the authors and/or other copyright owners and it is a condition of accessing publications that users recognise and abide by the legal requirements associated with these

- Users may download and print one copy of any publication from the public portal for the purpose of private study or research.

- You may not further distribute the material or use it for any profit-making activity or commercial gain

If the publication is distributed under the terms of Article $25 \mathrm{fa}$ of the Dutch Copyright Act, indicated by the "Taverne" license above, 


\section{'A place of greater safety'}

\section{Bespiegelingen over een Europees Statuut voor de strafrechtadvocaat}

Oratie

uitgesproken op vrijdag 10 oktober 2003 bij de aanvaarding van het ambt van bijzonder hoogleraar verdediging in strafzaken aan de Universiteit van Maastricht

door

Taru Spronken

De titel van deze oratie is ontleend aan de titel van de roman van Hilary Mantel, A place of greater safety, Penguin Books, 1993 over de Franse Revolutie en de lotgevallen van haar beroemde hoofdrolspelers Danton, Lacroix, Desmoulins en Robespierre, die in de nadagen van de revolutie, in weerwil van de revolutionaire leuze 'liberté, égalité et fraterité', zonder een noemenswaardige vorm van proces zijn geëxecuteerd.

Opmaak: Marjo Mullers

Engelse vertaling: Louise Rayar 
ISBN: 9013008496

(C) 2003, T. Spronken

Copyright tekst 
Mijnheer de rector magnificus,

Dames en heren,

\section{Inleiding}

De ontwikkelingen op het gebied van de strafrechtelijke samenwerking binnen de Europese Unie stellen de verdediging in strafzaken voor nieuwe uitdagingen. Alhoewel het al langer zo is dat onderzoeken in strafzaken van enige omvang zich niet tot de landsgrenzen beperken, is het gros van de strafrechtadvocaten nauwelijks bekend met de strafprocessuele praktijk buiten hun eigen land. Omdat de strafrechtelijke samenwerking binnen de EU momenteel vooral vorm krijgt door wederzijdse erkenning van beslissingen en uitspraken, zullen advocaten in toenemende mate worden geconfronteerd met de verschillenden rechtsordes van de EU waarin uiteenlopende materiële en procedurele regels worden toegepast. Naarmate de politiële en justitiële autoriteiten meer mogelijkheden worden geboden om transnationaal op te treden zullen meer verdachten geconfronteerd worden met opsporings- en vervolgingshandelingen buiten hun eigen land en zal de behoefte aan transnationale rechtsbijstand toenemen. In zaken waar grensoverschrijdend wordt opgespoord en vervolgd, zullen raadslieden uit verschillende landen met elkaar moeten samenwerken, verdedigingen zullen moeten worden gecoördineerd en er zal een grote behoefte ontstaan aan informatie over bewijs- en procedureregels in andere lidstaten.

Maar er is nog meer dat tot bezinning dwingt. De verschillenden nationale strafprocessuele systemen zijn diep geworteld in historische en culturele tradities, die ook hun weerslag hebben op de organisatie en de beroepsuitoefening van de advocatuur. Rol- en taakopvattingen van strafrechtadvocaten zijn nauw verbonden met de strafprocessuele systemen waarin zij functioneren. Bij grensoverschrijdende verdediging zullen advocaten geconfronteerd worden met verschillende beroepsopvattingen en gedragscodes die soms kunnen conflicteren. Er is momenteel een 
Groenboek over de Europese officier van justitie en een Groenboek Procedurele waarborgen voor verdachten in strafzaken, ${ }^{1}$ maar is het niet ook noodzakelijk dat Europese strafrechtadvocaten zich bezinnen over gemeenschappelijke standpunten aangaande de condities die een effectieve verdediging mogelijk moeten maken en hun taak- en rolopvatting daarbij? Zouden deze uitgangspunten niet moeten worden vastgelegd in bijvoorbeeld een Europees Statuut voor de strafrechtadvocaat? Voordat ik verder op deze vragen in ga, zal ik eerst de ontwikkelingen binnen de EU bespreken die het scenario vormen waarin de verdediging in strafzaken moet functioneren.

\section{2. 'A place of greater safety'}

Sinds het Verdrag van Amsterdam is het de aspiratie van de EU om de Europese burger een 'hoog niveau van zekerheid' en een 'ruimte van vrijheid, veiligheid en rechtvaardigheid' te verschaffen. ${ }^{2}$ Uit het Actieplan van de Raad en de Commissie van 3 december $1998,{ }^{3}$ waarin deze doelstelling nader wordt uitgewerkt, blijkt dat

1 Groenboek inzake de strafrechtelijke bescherming van de financiële belangen van de Gemeenschap en de instelling van een Europese officier van justitie, 11 december 2001 COM (2001) 715 definitief; Groenboek Procedurele waarborgen voor verdachten in strafzaken in de gehele Europese Unie, 19 februari 2003, COM (2003) 75.

2 Verdrag van Amsterdam houdende wijzigingen van het Verdrag betreffende de Europese Unie, de Verdragen tot oprichting van de Europese Gemeenschappen en sommige bijbehorende akten, ondertekend te Amsterdam, 2 oktober 1997, Pb. 1997 C 340/1. Zie voor een bespreking van de gevolgen voor het strafrecht van dit verdrag de Amsterdamse oratie van A.H.J. Swart, Een ware Europese rechtsruimte, Deventer: Gouda Quint 2001; A.H. Klip, Amsterdams Uniestrafrecht, NJB 1998, p. 711-716 en G.J.M. Corstens, Strafrechtspleging na het Verdrag van Amsterdam, NJB 1998, p. 804-808.

3 Actieplan van de Raad en de Commissie over hoe de bepalingen van het Verdrag van Amsterdam in zake de totstandkoming van een ruimte van vrijheid, veiligheid en rechtvaardigheid het best kunnen worden uitgevoerd, aangenomen door de Raad (Justitie en Binnenlandse Zaken) van 3 december 1998 Pb. 1999 C 19/1. 
vrijheid en veiligheid en rechtvaardigheid vooral worden opgevat als het gevrijwaard worden van criminaliteit:

- vrijheid wordt in het Actieplan gedefinieerd als het 'leven in een omgeving waar de wet wordt nageleefd, in de wetenschap dat de overheden afzonderlijk of gezamenlijk alles doen wat in hun macht ligt [....], om degenen die deze vrijheid trachten te ontkennen of misbruiken, te bestrijden en te bestraffen';

- veiligheid moet worden bereikt door een 'gemeenschappelijk optreden van de lidstaten op de onlosmakelijk met elkaar verbonden terreinen van politiële en justitiële samenwerking in strafzaken en zo de burgers niet alleen grotere veiligheid bieden, maar ook de belangen van de Unie te verdedigen, met inbegrip van haar financiële belangen' [...] 'In concreto betekent dit allereerst dat crimineel gedrag in de hele Unie even efficiënt moet worden aangepakt: terrorisme, corruptie, mensenhandel, georganiseerde misdaad moeten worden onderworpen aan gemeenschappelijke minimumregels ten aanzien van de elementen van strafbare feiten, en deze zouden, waar ze ook plaatsvinden, met dezelfde kracht moeten worden vervolgd';

- rechtvaardigheid 'moet worden gezien als het vergemakkelijken van het dagelijks leven van mensen en het ter verantwoording roepen van degenen die de vrijheid en veiligheid van individuen en de maatschappij bedreigen'.

\section{Marginalisering van rechtsbescherming}

Concrete aandacht voor vrijheid en rechtvaardigheid in de zin van rechtsbescherming tegen de (communautaire) overheid en het recht op een eerlijk proces is afgezien van vrij algemene verwijzingen naar het respecteren van individuele rechten en de toepasselijkheid van het $\mathrm{EVRM}^{4}$ - in het Uniestrafrecht nauwelijks terug

4 Zie bijvoorbeeld art. 6 van het Verdrag betreffende de Europese Unie, in werking getreden in februari 2003; Mededeling van de Commissie van 14 juli 1998 'Naar een ruimte van vrijheid, 
te vinden. ${ }^{5}$ Het Actieplan, dat met zeer gedetailleerde en uitgebreide plannen komt voor politionele en strafrechtelijke samenwerking tussen de lidstaten, is erg vaag als het gaat om rechtsbescherming en processuele waarborgen:

'Procedureregels zouden globaal dezelfde garanties moeten bieden, om ervoor te zorgen dat mensen niet ongelijk worden behandeld naar gelang van het rechtsgebied waar hun zaak wordt behandeld. In beginsel bestaan deze adequate en vergelijkbare procedurewaarborgen reeds dankzij de door het Europees Verdrag tot bescherming van de rechten van de mens en de fundamentele vrijheden geboden waarborgen en de dynamische interpretatie daarvan door het Europese Hof voor de rechten van de mens, met name waar het gaat om de rechten van de verdediging bij strafrechtelijke vervolgingen. Het lijkt evenwel nuttig om, in aanvulling op deze basisbeginselen, normen en gedragscodes vast te stellen op gebieden van transnationale relevantie en gebieden die van gemeenschappelijk belang zijn'

\section{$[\ldots]$}

'Problemen waarmee burgers onvermijdelijk worden geconfronteerd bij grensoverschrijdend procesvoering, hetzij in civiele, hetzij in strafzaken, moeten zo veel mogelijk worden ondervangen. Dit betekent bijvoorbeeld een efficiëntere toezending van documenten en informatie, gebruik van meertalige formulieren, het opzetten van mechanismen of netwerken om

veiligheid en rechtvaardigheid' COM (1998) 459 defin itief; Programma van maatregelen van de Raad om uitvoering te geven aan het beginsel van wederzijdse erkenning van strafrechtelijke beslissingen, 15 januari 2001, OJ C12; Groenboek inzake de strafrechtelijke bescherming van de financiële belangen van de Gemeenschap en de instelling van een Europese officier van justitie, COM (2001) 715 definitief.

5 Zie ook A.H. Klip, Unistrafrecht is op hol geslagen, NJB 1997, p. 667. 
bijstand te verlenen en te adviseren in transnationale zaken, en mogelijke regelingen voor rechtsbijstand.

\section{$[\ldots]$}

'Er dient te worden gestreefd naar doeltreffende procedurenormen die de rechtshulp bij strafzaken kunnen verbeteren, met eerbiediging van de eisen op het gebied van de fundamentele vrijheden. ${ }^{6}$

Ondertussen wordt de strafrechtelijke samenwerking tussen EU-lidstaten met grote voortvarendheid aangepakt. Daarbij is criminaliteitsbeheersing de dominante drijfveer. $^{7}$ Naast (concept-)kaderbesluiten die ten doel hebben strafbaarstellingen van bijvoorbeeld drugshandel, mensenhandel, seksuele uitbuiting van kinderen en kinderpornografie, racisme, witwassen en niet te vergeten terrorisme te harmoniseren, zijn er ook maatregelen getroffen om interstatelijke rechtshulp te vergemakkelijken door wederzijdse erkenning van nationale strafrechtelijke beslissingen tussen de lidstaten. Het Ontwerp voor een Europese Grondwet van 20 juni 2003 gaat nog verder en bevat bepalingen om tot harmonisatie van het materiële en formele strafrecht te komen. ${ }^{8}$

Het meest concrete voorbeeld van samenwerking is het Europees aanhoudingsbevel dat vanaf 1 januari 2004 voor alle 15 lidstaten van de Europese Unie in werking zal treden en dat alle bestaande uitleveringsprocedures binnen de Europese Unie zal vervangen. ${ }^{9}$ In de toekomst zal een aanhoudingsbevel op grond van een veroor-

6 Zie de punten 18, 19, 20 en 50 van het Actieplan.

7 Zie uitgebreider G.J.M Corstens en M.I. Veldt-Foglia, Communautarisering van het straf- en strafprocesrecht, Ontwikkelingen en grenzen, Preadvies voor de Vereniging voor de vergelijkende studie van het recht van België en Nederland, DD 2003, p. 103-177.

8 Ontwerp voor een Europese Grondwet d.d. 20 juni 2003, CONV 820/03; zie in dit verband G.J.M. Corstens, Het einde van het nationale strafrecht?, NJB 2003, p. 1429-1430.

9 Kaderbesluit van de Raad van 13 juni 2002 betreffende het Europees Aanhoudingsbevel en de procedure van overlevering tussen de lidstaten, $\mathrm{Pb}$. L 190 van 18 juli 2002, p. 1-18. 
deling of verdenking van een bepaalde persoon in de ene lidstaat, onvoorwaardelijk door de andere lidstaat moeten worden gerespecteerd. Behoudens een beperkt aantal weigeringsgronden, waarvan het grootste deel facultatief is, is iedere lidstaat verplicht tot het aanhouden en overdragen van personen - waaronder ook zijn eigen onderdanen - zonder dat nog wordt nagegaan of de vervolging en berechting van bepaalde strafrechtelijke delicten in overeenstemming zijn met de eigen normen en waarden van deze lidstaat. ${ }^{10}$ Het Europees aanhoudingsbevel heeft tot gvolg dat nationale strafbare feiten - dubbele strafbaarheid is als voorwaarde bij de in het kaderbesluit genoemde delictsoorten vervallen - binnen de gehele Europese Unie kunnen worden vervolgd. ${ }^{11}$

Omdat rechtswaarborgen vaak ten koste gaan van een gestroomlijnde interstatelijke samenwerking, gaat de versoepeling van Europese strafrechtelijke samenwerkingsvormen, zoals het Europees aanhoudingsbevel, gepaard met het afbreken van deze waarborgen voor de burger en verdachte. Dit wordt verantwoord geacht omdat de EU-staten een groot vertrouwen stellen in elkaars strafrechtsplegingen in die zin dat wordt uitgegaan van gelijkwaardige beschermingsniveaus. Of dit vertrouwen terecht is kan worden betwijfeld. Uit een inventarisatie van Smeulers en de Vries kan worden afgeleid dat onder de huidige en toekomstige lidstaten van de EU in bijna de helft van de staten in de mensenrechtensituatie zorgwekkende tot zeer zorgwekkende situaties zijn geconstateerd. ${ }^{12}$ Het gaat om discriminatie en racisme bij de politie, mishandeling op politieburo's, slechte detentieomstandigheden, lange duur van procedures en geen directe toegang tot rechtsbijstand van advocaten. ${ }^{13}$

10 Zie voor een overzichtelijke bespreking van het Europees Aanhoudingsbevel en de mogelijke weigeringsgronden A. Smeulers, Het Europees aanhoudingsbevel, MRT juli/augustus 2003.

11 Zie art. 2 Kaderbesluit betreffende het Europees Aanhoudingsbevel.

12 A. Smeulers en Jan de Vries, Het Europees aanhoudingsbevel: gerechtvaardigd vertrouwen?, NJCM-Bulletin 2003, p. 428-460.

13 Zie voor de tekortkomingen in de rechtsbijstand in strafzaken in de landen die binnenkort zullen toetreden tot de EU ook: Access to Justice in Central and Eastern Europe, Comparative Report november 2002, gepresenteerd op het European Forum on Access to Justice 5-7 December 2002 in Boedapest, te vinden op de website http://www.pili.org/library/access/country_reports.html. 
Bovendien bestaat er binnen de EU een grote diversiteit in rechtssystemen en iedere staat geeft zo zijn eigen invulling aan de verplichtingen die door het EVRM worden opgelegd, waardoor het niveau van rechtsbescherming tussen de staten aanzienlijk verschilt. Aan strafprocessuele rechtswaarborgen wordt in de accusatoire procesvormen van de common-law landen een andere invulling gegeven dan in de meer inquisitoire stelsels van de civil-law landen. ${ }^{14}$ Tussen landen zijn er grote verschillen in de lengte van strafrechtelijke procedures, toepassing van voorlopige hechtenis, in acceptatie van (anoniem) bewijsmateriaal, in mogelijkheden om te worden berecht bij verstek, in voorzieningen van gefinancierde rechtsbijstand en de mogelijkheid om in het vooronderzoek effectieve rechtsbijstand te krijgen. ${ }^{15}$ Het is niet voor niets dat de Europese regeringsleiders tijdens de top in oktober 1999 in Tampere geconcludeerd hebben dat wederzijdse erkenning van rechterlijke beslissingen, zijnde de hoeksteen van de justitiële samenwerking binnen de EU, gepaard zou moeten gaan met het vaststellen van gemeenschappelijke minimumnormen op het terrein van het strafprocesrecht. ${ }^{16}$

\section{Het Groenboek Procedurele waarborgen}

Om tegemoet te komen aan de kritiek dat de repressieve maatregelen in de EU niet gepaard gaan met flankerende maatregelen op het gebied van rechtsbescherming,

14 Zie voor de verschillen met de Noord-Europese staten, Noorwegen, Denemarken, Zweden en Finland: M. Boerlage en C.F. Mulder, Europa, het strafrecht en de rafelige noordgrens van de Europese Unie, DD 2003, p. 726-744.

15 Zie voor een zeer illustratieve case-study over de verschillende waardering van bewijs in het Verenigd Koninkrijk, Duitsland en Frankrijk: Analysis of the Green Paper on criminatlaw protection of the financial interests of the Community and the establishment of a European Prosecutor, Study commissioned by the Committee on Budgets of the European Parliament by Anke Biehler, Dr Sabine Gleß, Nina Parra, Dr Helge Elisabeth Zeitler, Max Planck Institute of Foreign and International Criminal Law, Freiburg/Br. April 2002, p. 38-46.

16 Conclusies van het voorzitterschap, Commissie van de Europese Gemeenschappen, Secretariaat Generaal, SI (1999) 800 samengevat in NJB 1999, p. 1831-1833. 
heeft de Commissie op 19 februari 2003 een Groenboek Procedurele waarborgen voor verdachten in strafzaken in de gehele Europese Unie (verder: Groenboek Procedurele waarborgen) gepresenteerd. ${ }^{17}$ De titel hiervan belooft meer dan de inhoud waar maakt. In het groenboek wordt aandacht besteed aan vijf - op zichzelf belangrijke - aspecten van rechtsbescherming, namelijk het recht op rechtsbijstand en tolkenbijstand, het recht op vertaling, informatierechten van de beschuldigde, bescherming van kwetsbare groepen en consulaire bijstand. Andere belangrijke strafprocessuele onderwerpen zoals de rechtmatige verkrijging van bewijs, het zwijgrecht, de presumptie van onschuld, recht op inzage van processtukken, de verplichting tot bekendmaken van ontlastend bewijsmateriaal, ne bis in idem, het recht op het horen van getuigen, vrijlating op borgtocht en berechting bij verstek zijn voor verdere studie naar voren geschoven, mede omdat deze onderwerpen volgens de Commissie geen prioriteit hebben. Zoals bij een groenboek gebruikelijk, is het bedoeld als consultatiedocument om te komen tot uniforme procedurele waarborgen. Hoewel het plan van de Commissie is om terzake van de procedurele waarborgen in 2004 te komen met een kaderbesluit is het gelet op de kritische reacties, ook van diverse regeringen, volstrekt onduidelijk wanneer en hoe concreet de voorstellen zullen worden uitgewerkt.

Verontrustend uit oogpunt van rechtsbescherming is, dat de maatregelen zoals het Europees aanhoudingsbevel al in werking treden, vóórdat enig zicht bestaat op de beantwoording van de vraag hoe de gemeenschappelijke minimumnormen op het terrein van het strafprocesrecht er uit zouden moeten uitzien. Het valt niet te verwachten dat hierover snel - of ooit -overeenstemming zal komen en de vrees bestaat dat indien dat wel gebeurt het niveau van rechtsbescherming zal worden genivelleerd. Harmonisering van procedurele waarborgen voor verdachten in de EU is gelet op het grote verschil in rechtssystemen die alle hun historische wortels hebben een bijzonder complexe - zo niet onhaalbare - aangelegenheid. Regels uit het

17 Groenboek Procedurele waarborgen voor verdachten in strafzaken in de gehele Europese Unie, 19 februari 2003, COM (2003) 75 definitief, zie met name punt 1.10 . 
ene processysteem laten zich niet zomaar inplanten in een ander systeem. ${ }^{18}$ Uit de moeizame wijze waarop uitspraken van het EHRM in de nationale rechtssystemen worden geïmplementeerd, blijkt dat lidstaten steeds kiezen voor de meest minimale aanpassingen om aan de eisen van het EVRM tegemoet te komen. Het is bijvoorbeeld voor Italië, topscoorder als het gaat om de schending van de redelijke termijn, kennelijk goedkoper en gemakkelijker om schadevergoedingen te betalen aan slachtoffers van een schending die zich de moeite nemen om in Straatsburg te klagen, dan de procedure zo in te richten dat verdachten binnen een redelijke termijn kunnen worden berecht. En zo zijn er nog meer voorbeelden te noemen. Nederland is al tot drie keer toe door het EHRM veroordeeld voor het gebruik van anonieme getuigenverklaringen en het is nog steeds de vraag of de wettelijke regeling bedreigde getuigen onder alle omstandigheden 'Straatsburg-proof' zal zijn. ${ }^{19}$ Ook de vaststelling door het EHRM dat de stelselmatige visitatie van gedetineerden in de Extra Beveiligde Inrichting in Vught een onmenselijke behandeling oplevert en dus een schending van artikel $3 \mathrm{EVRM},{ }^{20}$ leidt niet tot een wezenlijke verandering van de praktijk: in de nieuwe regeling wordt opgenomen dat visitatie in het vervolg alleen steekproefsgewijs plaatsvindt en vervolgens vinden er stelselmatig steekproeven plaats. ${ }^{21}$ De praktijk is weerbarstig en reageert op rechtswaarborgen die door verdragen worden opgelegd als een lichaam op transplantatie van vreemde

18 Zie in dit verband M.R. Damaska, Evidentiary Barriers to Conviction and Two Models of Criminal Procedure: A Comparative Study, 121 Pennsylvania Law Review 105, 1973 en M.R. Damaska, The Faces of Justice and State Authority, Yale University Press, New Haven and London 1986. Zie voor een meer theoretische benadering van het begrip harmonisering en de daarmee gepaard gaande moeilijkheden en vragen: A. Klip en H. van der Wilt (red.), Harmonisation and harmonising measures in criminal law, Royal Netherlands Academy of Arts and Sciences, Amsterdam 2002.

19 EHRM 20 november 1989, Kostovski, NJ 1990, 245; EHRM 23 november 1997, Van Mechelen, NJ 1997, 635 en EHRM 14 februari 2002, Visser, European Human Rights Cases (EHRC) 2002, 27.

20 EHRM 4 februari 2003, Lorsé e.a., nr. 52750/99, EHRC 2003, 26.

21 Naar aanleiding hiervan heeft de president in kort geding de Staat bevolen om de steekproefsgewijze visitatie buiten toepassing te laten, President Rb. Den Haag 7 juli 2003, KG 03/624, ten tijde van de afsluiting van deze tekst nog niet gepubliceerd. 
organen. Het systeem probeert ze eerst af te stoten en als dat niet lukt worden ze geassimileerd. $^{22}$

Tegen wederzijdse erkenning van strafrechtelijke en strafprocessuele beslissingen lijkt bij de EU-lidstaten nauwelijks principiële bezwaren te bestaan omdat het hierbij gaat om interstatelijke samenwerking waarbij de nationale autonomie ten aanzien van het strafprocessuele systeem intact blijft en alle staten de voordelen van samenwerking voor een effectieve criminaliteitsbestrijding wel zien. Tegen het van bovenaf - vanuit de Europese instellingen - vaststellen van concrete procedurele waarborgen bestaat veel meer weerstand. Uit de reacties van lidstaten op het Groenboek Procedurele waarborgen blijkt, dat veel staten zich op het standpunt stellen dat voor een goede justitiële samenwerking tussen de lidstaten helemaal geen noodzaak bestaat tot het vastleggen van een minimum standaard van procedurele waarborgen voor verdachten, nu deze standaard al door het EVRM wordt grealiseerd. $^{23}$

\section{Voorwaarden voor effectieve rechtsbescherming}

Rechtsbescherming wordt niet vanzelf gerealiseerd door het onderschrijven van uitgangspunten van een eerlijk proces. Aan deze uitgangspunten zal concrete invulling moeten worden gegeven wil er enig tegenwicht worden gevormd voor de maatregelen die de bevoegdheden van openbare aanklagers, gerechtelijke instanties en opsporingsambtenaren verruimen. In dat opzicht zijn de pogingen die in het groenboek worden gedaan om te komen tot een praktische en efficiënte invulling

22 Zoals mijn collega Ties Prakken in haar oratie beeldend heeft uitgedrukt: T. Prakken, Beginselen van een goede verdediging, Deventer: Gouda Quint 1999, p. 6.

23 Zie de standpunten van Duitsland, Ierland, Oostenrijk, Verenigd Koninkrijk, Nederland naar aanleiding van het Groenboek, voorafgaande aan de publieke hoorzitting van de Commissie van 16 juni 2003. Alleen Finland en het toekomstige EU-lid Tsjechië heeft zich tot nu toe (juli 2003) uitgesproken vóór het vaststellen van procedurele minimum-garanties. 
van procedurele waarborgen in alle landen van de EU, te prijzen. De Commissie plaatst dit initiatief echter voornamelijk in het teken van het bewerkstelligen van wederzijds vertrouwen tussen lidstaten om te komen tot strafrechtelijke samenwerking $^{24}$ en heeft daarbij onvoldoende oog voor het spanningsveld dat tussen het optimaliseren van waarborgen voor verdachten en een gestroomlijnde internationale samenwerking bestaat. Bovendien gaat de Commissie te gemakkelijk voorbij aan de grote verschillen tussen de processystemen binnen de EU. ${ }^{25}$

\section{Een Europees Statuut voor de Strafrechtadvocaat?}

Tot nu toe is er door de CCBE ${ }^{26}$ sommige Europese balies en organisaties van strafadvocaten steeds op ad hoc basis gereageerd op initiatieven vanuit de EU, zonder dat daar een samenhangende analyse vanuit het verdedigingsperspectief aan ten grondslag ligt. In mijn inleiding heb ik de vraag gesteld of het niet noodzakelijk is dat Europese strafrechtadvocaten zich bezinnen over gemeenschappelijke standpunten aangaande de condities die een effectieve verdediging mogelijk moeten maken en hun taak- en rolopvatting daarbij en of dit niet zou moeten resulteren in een Europees Statuut voor de strafrechtadvocaat. Mijns inziens kan deze vraag alleen bevestigend worden beantwoord. De ontwikkelingen op EU niveau, of deze nu gaan in de richting van harmonisatie of van federalisatie, zijn nauwelijks te stuiten en onmiskenbaar eenzijdig gericht op de repressieve kant van het strafrecht. Processuele waarborgen worden daaraan ondergeschikt gemaakt. In het kielzog hiervan worden ook tot voor kort nog als vanzelfsprekend beschouwde waarborgen in

24 Zie $\S 1.7$ van het Groenboek Procedurele waarborgen.

25 Dit wordt helder geillustreerd in het hiervoor al genoemde onderzoek: Analysis of the Green Paper on criminallaw protection of the financial interests of the Community and the establishment of a European Prosecutor, Study commissioned by the Committee on Budgets of the European Parliament by Anke Biehler, Dr Sabine Gleß, Nina Parra, Dr Helge Elisabeth Zeitler, Max Planck Institute of Foreign and International Criminal Law, Freiburg/Br. April 2002.

26 Consultative Committee of the Bars and Law Societies of the European Community. 
het kader van de rechtsbijstand, zoals de bescherming van het beroepsgeheim, bedreigd, waarover later meer. ${ }^{27}$ Dat heeft ingrijpende gevolgen voor de rechtsbescherming en de rechtsbijstand. Het is de taak van de (communautaire) overheid om de procedurele randvoorwaarden scheppen om rechtsbijstand aan verdachten mogelijk te maken. Het geven van inhoud aan rechtsbescherming is echter bij uitstek een verantwoordelijkheid van de Europese Balies en de organisaties van strafadvocaten zelf. ${ }^{28}$ Gelet op de Europese (maar ook mondiale) ${ }^{29}$ ontwikkelingen is het hard nodig dat vanuit de beroepsgroep, die tot taak heeft om op te komen voor de fundamentele rechten van verdachten, wordt aangegeven waar zij voor staat, hoe zij haar functie opvat en welke faciliteiten en garanties zij nodig heeft om haar werk te kunnen doen. Deze uitgangspunten, vastgelegd in een Statuut, kunnen dienen om zowel op Europees als nationaal niveau stelling te nemen tegen de afkalving van de rechtsbescherming. De volgende vraag is natuurlijk wat een dergelijk Statuut zou moeten inhouden. Die vraag is moeilijker te beantwoorden en zal nog onderzoek en discussie vergen. Tot deze discussie wil ik hier een aanzet doen. Daarbij wil ik mij beperken tot die procedurele waarborg voor de verdachte die

27 Zie hierna § 9 onder het kopje Vertrouwelijke communicatie.

28 Zie in dit verband Recommendation Rec (2000) 21 of the Committee of Ministers to member states on the freedom of excercise of the profession of lawyer adopted on 25 October 2000, waarin onder 'Principle III- Role and duty of lawyers' onder andere is opgenomen: 'Bar associations or other lawyers' professional associations should draw up professional standards and codes of conduct and should ensure that, in defending the legitimate rights and interests or their clients, lawyers have a duty to act independently, diligently and fairly'; Conclusions Council of Europe, The role and the responsabilities of the lawyer in a society in trans ition, 9-11 december 1997 Budapest (97) Concl. en The Declaration of Perugia on the Principles of Professional Conduct of the Bars and Law Societies of the European Community 16 september 1977 van de CCBE.

29 Zie de Overeenkomst betreffende uitlevering tussen de Europese Unie en de Verenigde Staten van Amerika, Pb. 19 juli 2003 L 181, p. 27, de Overeenkomst betreffende de wederzijdse rechtshulp in strafzaken tussen de Europese Unie en de Verenigde Staten van Amerika 2003/517/EC, Pb. 19 juli 2003 L 181, p. 34 en het Besluit van de Raad van 6 juni 2003 inzake de ondertekening van de overeenkomsten tussen de Europese Unie en de Verenigde Staten van Amerika. 
onlosmakelijk verbonden is met de taak van de strafrechtadvocaat, namelijk het recht van de verdachte op rechtsbijstand.

\section{De relatie tussen het recht op rechtsbijstand en andere procedurele waar- borgen}

Het recht op rechtsbijstand onderscheidt zich van andere procedurele waarborgen zoals bijvoorbeeld het recht om geïnformeerd te worden over de beschuldiging, het zwijgrecht, het nemo-teneturbeginsel, het recht op het horen van getuigen, kortom de hele catalogus aan procedurele waarborgen die in internationale verdragen en nationale strafprocessuele regelingen zijn vastgelegd, doordat het recht op rechtsbijstand een noodzakelijk voorwaarde vormt voor de verdachte om zich op een effectieve manier te kunnen verdedigen en gebruik te kunnen maken van de andere aan hem toegekende waarborgen.

De Commissie beschouwt in het Groenboek Procedurele waarborgen het recht op rechtsbijstand als 'de grondslag van alle andere rechten' ${ }^{30}$ Ik zou dit zo niet willen formuleren. De grondslag van alle aan de verdachte toebedeelde rechten - inclusief het recht op rechtsbijstand - is immers, dat de verdachte in staat moet worden gsteld zich te verdedigen en daarbij een eerlijke kans moet krijgen. Het recht op verdediging is een van de essentiële grondbeginselen van een eerlijk proces. Dat wordt onderstreept door het feit dat art. 6 EVRM - waarin het recht op verdediging in strafzaken expliciet is opgenomen - in tegenstelling tot andere verdragsbepalingen zoals art. 5 , art. 8 en art. $10 \mathrm{EVRM},{ }^{31}$ geen beperkingsgronden kent, in het belang van bijvoorbeeld de democratische samenleving of de openbare veiligheid. De uitgangspunten van een eerlijk proces - waaronder ook het recht op een effectieve verdediging - zijn immers als zodanig in het belang van een democratische samen-

30 Groenboek Procedurele waarborgen $\S 2.5$.

31 Respectievelijk het recht op bescherming van persoonlijke vrijheid, privacy en vrijheid van meningsuiting. 
leving. Alhoewel bepaalde verdedigings rechten kunnen worden beperkt, is het recht op verdediging absoluut. ${ }^{32}$ Rechtsbijstand is daarom niet de grondslag van de verdedigingsrechten, maar een noodzakelijke voorwaarde om de verdedigingsrechten effectief te kunnen uitoefenen.

Daarbij is het van belang om te onderkennen dat art. 6 lid 3 c EVRM de verdachte het recht geeft om zowel zichzelf te verdedigen als zich te laten bijstaan door een raadsman. Hierbij gaat het niet om twee gelijkwaardige alternatieven in die zin dat de ene vorm van verdediging door de andere zou kunnen worden vervangen. ${ }^{33}$ Beide vormen van verdediging hebben een eigen processuele functie, de verdachte brengt zijn persoonlijkheid en kennis over de feiten en omstandigheden in en de raadsman zijn juridische kennis en procedurele ervaring. Voorop blijft staan dat de

32 Dit blijkt bijvoorbeeld uit de rechtspraak van het EHRM op het gebied van het horen van (anonieme) getuigen. In de Kostovski-zaak overwoog het EHRM: 'Although the growth in organised crime doubtless demands the introduction of appropriate measures, the Government's submissions appear to the Court to lay insufficie nt weight on what the applicant's counsel described as 'the interest of everybody in a civilised society in a controllable and fair judicial procedure'. The right to a fair administration of justice holds so prominent a place in a democratic society (see the Delcourt judgment of 17 January 1970, Series A no. 11, p. 15, § 25) that it cannot be sacrificed to expediency. Ondervragingsbevoegdheden kunnen worden beperkt maar nooit in die mate dat verdediging onmogelijk wordt. De standaardoverweging van het EHRM is: 'In addition, all the evidence must normally be produced at a public hearing in the presence of the accused, with a view to adversarial argument. There are exceptions to this principle, but they must not infringe the rights of the defence', zie $\S 51$ in de Van Mechelen-zaak.

33 Zie M. Spaniol, Das Recht auf Verteidigersbeistand im Grundgezetz und in der Europäischen Menschenrechtskonvention, Berlin: Duncker \& Humblot, 1990, p. 63-64 en bijvoorbeeld ECRM 27 oktober 1998, H.N. v. Italy, nr. 18902/91; EHRM 12 februari 1985, Colozza, NJ 1986, 685, § 27; EHRM 6 december 1988, Barbera e.a., A 146, § 78; EHRM 21 september 1993, Kremzow, NJ 1994, 359, § 45 en EHRM 25 november 1997, Zana, Reports 1997-VII, § 67-72. In dezelfde zin heeft het Mensenrechtencomité zich uitgelaten in HRC 2 april 1997, Michael and Brian Hill v. Spain, U.N. Doc. CCPR/C/59/526/1993, waarin een klacht tegen Spanje gegrond werd verklaard omdat aan Michael Hill, die geen rechtsbijstand wenste, volgens het Spaanse recht niet was toegestaan zichzelf te verdedigingen. Het Mensenrechtencomité achtte dit in strijd met art. 14 lid 3d IVBPR. 
verdachte in beginsel het recht heeft zichzelf te verdedigen en af te zien van bijstand door een advocaat. ${ }^{34}$

Dat dit laatste niet altijd als vanzelfsprekend wordt beschouwd blijkt uit een aantal zaken die hebben gespeeld bij het Joegoslavië- en het Rwanda-Tribunaal. Het ging daarbij om de vraag of een verdachte recht heeft op toevoeging van een advocaat van eigen keuze en of aan een verdachte die hetzij zichzelf wil verdedigen, hetzij zich helemaal niet wil verdedigen tegen diens wil een advocaat kan worden toegevoegd. Ten aanzien van de vrije advocatenkeuze heeft het Rwanda-Tribunaal het standpunt ingenomen dat, hoewel met de keuze van de verdachte in beginsel rekening dient te worden gehouden, het recht op vrije advocatenkeuze niet van toepassing is bij toegevoegde rechtsbijstand. ${ }^{35}$ Het Joegoslavië-Tribunaal daarentegen lijkt bij toegevoegde rechtsbijstand wel de keuze van de verdachte voorop te stellen. ${ }^{36}$ In een zaak waarbij een verdachte zijn advocaat verboden had namens hem op te treden omdat hij het Rwanda-Tribunaal als zodanig niet wenste te erkennen en de betrokken advocaat het Tribunaal had verzocht hem van zijn verplichtingen te ontslaan, werd dit verzoek niet gehonoreerd omdat de verdachte volgens het Tribunaal slechts uit was op obstructie van de rechtsgang. ${ }^{37}$ In de zaak tegen Milose-

34 Zie art. 6 lid 3 EVRM waarin staat vermeld dat de verdachte het recht heeft 'zichzelf te verdedigen of daarbij de bijstand te hebben van een raadsman naar eigen keuze' en art. 14 lid 3d IVBPR bepaalt: 'zichzelf te verdedigen of de bijstand te hebben van een raadsman naar eigen keuze'. Volgens het EHRM betekent dit dat de verdachte in beginsel altijd het recht heeft om bij zijn berechting aanwezig te zijn en om te participeren in het proces. Zie bijvoorbeeld: EHRM 12 februari 1985, Colozza, NJ 1986, 685, § 27 en EHRM 16 december 1999, T. v. United Kingdom, nr. 24724/94, § 88 en 89. Alleen in appel en cassatiezaken kan hierop een uitzondering worden gemaakt als deze zaken beperkt zijn tot een puur juridische toets, waarbij geen feiten ter discussie staan of waarbij de strafmaat niet wordt vastgesteld, zie EHRM 10 februari 1996, Botten, Reports 1996-I, § 39.

35 Judgment of the Appeals Chamber of 19 October 2000, Kambanda v. Prosecutor, Case No. ICTR 97-23-A en Judgment Appeals Chamber ICTR of 1 June 2001, Prosecutor v. Akayesu, Case No. ICTR-96-4.

36 Prosecutor v. Zoran Kupreškic and others, Decision on Defence Request for Assignment of Counsel ICTY, 10 march 1998, Case No. IT-95-16-T.

37 Decision (Request for Withdrawal of Defence Counsel), Barayagwizwa v. Prosecutor, Case No. ICTR-96-3-A, President ICTR, 7 July 2000. 
vic heeft het Joegoslavië-Tribunaal uitgemaakt dat alhoewel het recht van een verdachte zichzelf te verdedigen niet absoluut is, aan een verdachte die competent en gezond is en de wens te kennen geeft zichzelf te willen verdedigen, geen rechtsbijstand mag worden opgedrongen. In deze zaak koos het Joegoslavië-Tribunaal voor de wat hibride oplossing van het aanstellen van Amicus Curiae die het Tribunaal dienden te adviseren in het belang van de verdediging. ${ }^{38}$ Recentelijk heeft het Joegoslavie-Tribunaal echter een zogenaamde 'standby counsel' tegen de wil van een verdachte toegevoegd en daarbij bepaald dat deze 'standby counsel' op verzoek van het Tribunaal opmerkingen kan maken in het belang van de verdediging en getuigen kan ondervragen indien de verdachte - die het recht gelaten wordt zichzelf te verdedigen - zich obstructief gedraagt. ${ }^{39}$

Naar mijn mening zijn de beslissingen waarbij aan een verdachte tegen zijn wil een advocaat wordt toegevoegd in strijd met zijn recht op een eerlijk proces. Een verdachte kan immers niet gedwongen worden om actief te participeren in de tegen hem aanhangig gemaakte strafvervolging. ${ }^{40}$ Indien de verdachte ervoor kiest om zich niet te verdedigen, wat daarvoor zijn redenen ook mogen zijn, dan dient dit in beginsel te worden gerespecteerd. Het recht op verdediging en rechtsbijstand is immers geen verplichting. Bovendien is een advocaat die niet het vertrouwen gniet van de verdachte niet in staat een goede verdediging voeren omdat de verdachte in dit soort gevallen geen overleg wil met de betrokken advocaat. Daarnaast worden de advocaten ook in een onmogelijke ethische positie geplaatst. Alle gdragscodes schrijven voor dat een advocaat niet tegen de wil van een cliënt kan en mag optreden. De reden daarvoor lijkt evident: een cliënt moet zijn eigen keuzes

38 ICTY 4 April 2003, Reasons for Decision on the Prosecution Motion concerning Assignment of Counsel, Prosecutor v. Miloševic, Case No. IT-02-54 en ICTY 31 August 2001, Order Inviting Designation of Amicus Curiae, Prosecutor v. Milosevic, Case No. IT-02-54

39 ICTY 9 may 2003, Decision on Prosecution's Motion for Order Appointing Counsel to Assist Vojislav Seselj with his defence, Prosecutor v. Vojislav Seselj, Case No. IT-03-67-PT.

40 Zie EHRM 10 December 1982, Corigliano, A 57 waarin het Hof overweegt: - it should be recalled that Article 6 does not require the person concerned actively to co-operate with the judicial authorities'. 
kunnen maken en niet slechter af zijn mét advocaat, dan zonder advocaat. Een advocaat verplichten tot bijstand tegen de wil van de cliënt is vergelijkbaar met dwangvoeding bij een hongerstaker: hierdoor wordt het zelfbeschikkingsrecht aangetast. ${ }^{41}$ Voornoemde beslissingen van de Tribunalen zijn dan ook meer in gegeven door het belang van de voortgang van de procedures, dan in het belang van een eerlijk proces waarin in beginsel de proceshouding die de verdachte aanneemt dient te worden gerespecteerd. ${ }^{42}$

\section{Taak en functie van de strafrechtadvocaat}

De kern van de taak van de raadsman is gelegen in het waarborgen van de vrijheid van de individuele verdachte om in het strafproces voor zijn belangen op te komen. Daarbij is de functie van de raadsman niet beperkt tot de beïnvloeding van het strafproces ten gunste van de verdachte. Hij heeft daarnaast ook de taak om de verdachte, die door een vervolging zowel psychisch als sociaal zwaar wordt belast, bij te staan. ${ }^{43}$ Centrale uitgangspunten die de positie van de raadsman bepalen zijn: partijdigheid, onafhankelijkheid en het bestaan van een vertrouwensrelatie met de cliënt. Deze uitgangspunten zijn ook onderling verbonden:

41 Door de tribunalen wordt uitvoerig verwezen naar de zaak Croissant, EHRM 25 septe mber, NJ 1993, 526, waarin het EHRM heeft overwogen dat het in het belang van de rechtspleging kan zijn, dat een verdachte wordt bijgestaan door een advocaat, ook al stelt hij daar zelf geen prijs op. Zoals uit mijn stellingen blijkt ben ik het hiermee niet eens. Het is mijns inziens in het belang van de rechtspleging dat de vrijheid van de verdediging wordt gerespecteerd. Overigens vraag ik mij af of het EHRM de zaak op dezelfde manier had afgedaan als Croissant niet tevens werd bijgestaan door twee door hemzelf gekozen advocaten, een aspect waarmee het EHRM bij de beoordeling van de zaak rekening hield.

42 Zie in gelijke zin: Daniel D. Ntanda Nsereko, Ethical obligations of counsel in criminal proceedings: representing an unwilling client, 12 Criminal Law Forum 2001, p. 487-507.

43 Zie in dit verband ECRM 12 juli 1984, Can, B 79. 
- Partijdigheid is noodzakelijk omdat rechtsbijstand in de eerste plaats dienstverlenend is in die zin dat deze in het teken staat van de individuele vrijheid van de verdachte die in beginsel zelf bepaalt hoe hij zijn verdediging wil voeren. Partijdigheid is ook een noodzakelijk element van een contradictoire procedure en van belang voor een evenwichtige waarheidsvinding. Tot slot veronderstelt partijdigheid een zekere mate van solidariteit met de verdachte en is deze een voorwaarde voor het kunnen opbouwen van een vertrouwensrelatie.

- Onafhankelijkheid heeft ook verschillende functies en betekenissen. De advocaat moet zich onafhankelijk kunnen opstellen tegenover de overheid, het publiek en andere betrokken procespartijen. Dit aspect van onafhankelijkheid dient als waarborg voor partijdigheid: de advocaat moet zich laten leiden door de belangen van zijn cliënt, ook al komt dit in strijd met de belangen van de overheid of derden en ook al staat hij onder druk van de publieke opinie.

Onafhankelijkheid heeft echter ook een functie in de relatie met de cliënt. De advocaat zal op grond van zijn professionele kennis van het strafproces als een deskundig klankbord moeten fungeren voor zijn cliënt en hem moeten behoeden voor nadelige beslissingen. Een cliënt heeft pas baat bij de deskundigheid van de advocaat als deze wat meer afstand neemt van de zaak en een reële inschatting maakt van diens procespositie en verdedigingsmogelijkheden.

Verder heeft de onafhankelijkheid ook een functie om de advocaat de ruimte te geven in zijn optreden zekere grenzen in acht te nemen. Hij mag niet handelen in strijd met de wet en ook geen misbruik maken van zijn privileges, zoals bij voorbeeld het recht op vrij verkeer. Dit aspect van onafhankelijkheid bindt de partijdige belangenbehartiging aan beginselen van proportionaliteit en subsidiariteit en houdt tevens in dat de belangenbehartiging alleen met rechtmatige middelen mag worden nagestreefd. In deze betekenis van onafhankelijkheid zit een spanningsveld, in die zin dat de belangen van de cliënt tegenstrijdig kunnen zijn aan de belangen van een behoorlijke beroepsuitoefening. In dit kader wordt ook 
wel verwezen naar het belang van de rechtspleging of 'the interests of justice' ${ }^{44}$ Cruciaal daarbij is wat onder het belang van de rechtspleging wordt verstaan en daarover wordt wel eens verschillend gedacht. Soms wordt het belang van de rechtspleging gelijkgesteld aan de belangen van criminaliteitsbestrijding en wordt van de advocaat verwacht dat hij ook met die belangen bij zijn verdediging rekening houdt. In mijn optiek is dit geen juiste invulling van het begrip 'interests of justice'. Een behoorlijke beroepsuitoefening van de advocaat in strafzaken behoort - weliswaar binnen de kaders van de wet - altijd primair gebonden te zijn aan de bescherming van de rechten van de mens ten opzichte van de macht van de staat en het belang van de criminaliteitsbestrijding. Een dergelijke beroepsuitoefening kan wel eens op gespannen voet staan met een efficiënte strafvervolging, maar nooit strijdig zijn met het belang van de rechtspleging of het openbaar belang. Immers tot deze belangen behoort ook dat een verdachte aanspraak kan maken op een adequate en partijdige verdediging.

- De vertrouwensrelatie is tot slot de belangrijkste voorwaarde om als verdediger te kunnen optreden. De verdachte moet open en vrij met zijn advocaat kunnen

44 Zie in dit verband de preambule van de Gedragscode voor de advocaten van de Europese Unie, laatstelijk gewijzigd op 6 december 2002, waarin staat vermeld: 'A lawyer must serve the interests of justice as well as those whose rights and liberties he is trusted to assert and defend and his duty is not only to plead his client's cause but to be his adviser. A lawyers function therefore lays on him a variety of legal and moral obligations (sometimes appearing to be in conflict with each other)'. Zie ook de inleiding op de Gedragsregels 1992 van de Nederlandse Orde van Advocaten waarin staat vermeld dat de behartiging van de aan de advocaat toevertrouwde belangen van zijn cliënt zijn eerste taak is, 'doch dat hij deze taak dient te verrichten in overeenstemming met het openbaar belang bij een behoorlijke beroepsuitoefening, waarvoor een enkele maal zelfs het belang van zijn cliënt zal moeten wijken'. In de common-law landen zoals Engeland en Ierland, waar de advocaat tevens 'officer of the court' is, wordt bij een conflict van plichten aangenomen dat de verplichtingen tegenover het gerecht, bijvoorbeeld als het gaat om mogelijke misleiding van het gerecht, voorrang hebben boven de belangen van de cliënt. Dit uitgangspunt dient echter niet los te worden gezien met de taak en functie van de advocaat in de Angel Saksische adversaire procesvorm. Zie bijvoorbeeld P.J. Baker, Lawyers Duties to the Court, The Law Quarterly Review, 1998, p. 103; Meredith Blake and Andrew Ashworth, Some Ethical Issues in Prosecuting and Defending Criminal Cases, Criminal Law Review 1998, p 16-34. 
communiceren zonder dat hij hoeft te vrezen dat hetgeen hij de advocaat toevertrouwt naar buiten wordt gebracht of tegen hem wordt gebruikt. Hij moet kunnen rekenen op onafhankelijk en deskundig advies, waarbij de advocaat zijn belangen vooropstelt. De vertrouwensrelatie houdt ook in dat van beide zijden de vrijheid moet bestaan om de relatie te beëindigen als er sprake is van een onoverkomelijke vertrouwensbreuk. Als een cliënt geen vertrouwen meer heeft in zijn advocaat is de basis voor rechtsbijstand vervallen en zal de advocaat zich moeten terugtrekken.

\section{Garanties voor een adequate rechtsbijstand}

\section{Moment van aanvang}

Het strafproces dient voor de realisering van het recht op bijstand een aantal waarborgen te bevatten. In de eerste plaats moet het recht zelf in het strafproces worden gedefinieerd en vastgelegd. Dat geldt ook voor het moment waarop het recht op bijstand ontstaat. In het Groenboek Procedurele waarborgen wordt als uitgangspunt gehanteerd dat het recht op rechtsbijstand onmiddellijk na de aanhouding ontstaat en dat de verdachte recht heeft op rechtsbijstand gedurende het hele stadium van verhoor en ondervraging. Dit is binnen de verschillende jurisdicties van de EU een precair punt, waarbij de principiële verschillen van de grondslagen van de AngelSaksische processystemen en de inquisitoire continentale systemen het duidelijkste aan het licht komen. Terwijl het recht op bijstand tijdens het politieverhoor in de common-law landen regel is, omdat de verdachte in deze systemen geen voorwerp van onderzoek is maar vrij is om zijn procespositie te bepalen, bestaat dit recht in veel continentale landen, zoals bijvoorbeeld Nederland, België en Frankrijk niet. De fase van het politieverhoor is in de inquisitoire processystemen voor de verdachte de meest cruciale, omdat zijn verklaringen voor het bewijs kunnen worden gebruikt. In deze fase moet de verdachte vitale beslissingen nemen ten aanzien van de door hem in te nemen proceshouding, met name of hij zich al dan niet op zijn zwijgrecht zal beroepen, met verstrekkende gevolgen voor het verdere verloop van de tegen hem ingestelde strafvervolging. De reden dat aan verdachten tijdens het 
politieverhoor rechtsbijstand wordt onthouden is de vrees dat de anwezigheid van de raadsman een hindernis is op de weg naar een bekentenis van de verdachte en dus een negatieve invloed heeft op de waarheidsvinding. In de inquisitoire systemen is het recht op bijstand in de voorfase van het strafproces dan ook geen algemeen recht, maar een recht dat ondergeschikt is aan het onderzoeksbelang. Uit de jurisprudentie van het EHRM komt naar voren dat de verdachte in ieder geval een advocaat moet kunnen consulteren in de eerste fase van de politieverhoren, zeker als de verdachte belangrijke beslissingen moet nemen die consequenties hebben voor het verdere verloop van de vervolging. ${ }^{45}$ In de zaak Dougan heeft het EHRM echter overwogen dat de verdachte aan artikel 6 EVRM niet het recht kan ontlenen zijn advocaat bij de politieverhoren aanwezig te laten zijn. ${ }^{46}$ Opmerkelijk is dat het EHRM hierbij afwijkt van de aanbevelingen van het CPT en de statuten van de internationale oorlogstribunalen. ${ }^{47}$ Gelet op het zwijgrecht van de verdachte, dat in alle EU-jurisdicties - waaronder ook de inquisitoire - wordt erkend, valt niet in te zien waarom het onderzoeksbelang een legitiem argument zou kunnen zijn om de verdachte tijdens de politieverhoren rechtsbijstand te onthouden. Juist in de fase van het politieverhoor heeft de verdachte behoefte aan voorlichting, advies en steun. Het recht op bijstand tijdens de politieverhoren zou dan ook algemeen gegarandeerd moeten worden.

Verder is het van belang dat, indien er sprake is van grensoverschrijdende strafzaken, aan de verdachte recht wordt toegekend op zowel rechtsbijstand in het land waar hij verblijft, als in het land waarin tegen hem onderzoeks- of vervolgingshan-

45 Zie bijvoorbeeld EHRM 8 februari 1996, Murray, NJ 1996, 725; EHRM 2 mei 2000, Condron, no. 35718/97; EHRM 6 juni 2000, Magee, nr. 28135/95 en EHRM 06 juni 2000, Averill, nr. 36408/97, NJB 2000, 33, p. 1631

46 EHRM 14 december 1999, Dougan, no. 44738/98.

47 Zie art. 55 lid 2d van het Statuut van Rome en art. 18 van het Statuut van het Internationaal Joegoslavië-Tribunaal. 
delingen worden ingesteld. Hierover wordt in het Groenboek Procedurele waarborgen in zijn geheel niet gerept. ${ }^{48}$

\section{Toegevoegde rechtsbijstand}

Een van de hoekstenen van het recht op rechtsbijstand is dat hierin van overheidswege wordt voorzien indien de verdachte niet zelf een advocaat kan betalen. In de meeste EU-lidstaten is er een toevoegingssysteem, maar het zwakke punt zit in de vergoeding van de toegevoegde advocaat. Binnen de EU worden alleen in het Verenigd Koninkrijk en Ierland toegevoegde advocaten behoorlijk betaald. In de overige EU lidstaten kunnen de vergoedingen nauwelijks de (kantoor)kosten van de advocaat dekken of zijn zij zo laag dat er eigenlijk van pro deo rechtsbijstand kan worden gesproken. Dat is niet bevorderlijk voor de kwaliteit van de rechtsbijstand. Immers daar waar advocaten verplicht worden toegevoegde bijstand in strafzaken te verlenen, als een soort beroepsverplichting zonder dat er een redelijke vergoeding tegenover staat, wordt de rechtsbijstand vaak overgelaten aan onervaren jonge advocaten of wordt aan de rechtsbijstand minimale tijd besteed. ${ }^{49}$ In het Groenboek procedurele waarborgen wordt aan dit aspect aandacht besteed en de vraag gesteld in hoeverre lidstaten verplicht kunnen worden om toegevoegde advocaten zodanige vergoedingen te verstrekken dat het bijstaan van onvermogende verdachten aantrekkelijk is. Gelet op de financiële repercussies van adequate vergoedingen reageren de meeste lidstaten afhoudend op deze vraag van de Commissie. De CCBE stelt in haar reactie op het Groenboek voor, een onderzoek in iedere lidstaat te laten verrichten om te bezien in hoeverre het systeem van toevoegingen leidt tot effectieve

48 Op dit punt wordt gewezen in de Stellungnahme der Strafverteidigervereinigungen und der Arbeitsgruppe eu-defence zum Greenpaper from the Commission Procedural Safeguards for Suspects and Defendants in Ciminal Proceedings throughout the European Union van 24 mei 2003, te raadplegen op de website: <www.organisation.strafverteidigervereinigungen.org>.

49 Overigens heeft het EHRM in de zaak Van der Mussele tegen België, EHRM 23 november 1983, A 70, een klacht van Van der Mussele wegens schending van art. 4 EVRM (verbod van dwangarbeid) omdat hij als advocaat-stagiaire verplicht werd zonder vergoeding rechtsbijstand te verlenen aan een verdachte in een strafzaak, ongegrond verklaard, kort samengevat omdat het verlenen van pro-deo bijstand bij het beroep van advocaat behoort. 
rechtsbijstand en of de vergoedingen voldoende zijn om ook gekwalificeerde advocaten aan het toevoegingensysteem te laten deelnemen. ${ }^{50}$ Een dergelijk onderzoek lijkt mij van groot belang, want de effectiviteit en kwaliteit van de verdediging staat of valt met een goed functionerend toevoegingssysteem.

Tot slot zou moeten gelden dat aan de verdachte in beginsel een advocaat van eigen keuze dient te worden toegevoegd, indien betrokken advocaat bereid en in staat is de verdediging op zich te nemen. In de meeste lidstaten wordt dit uitgangspunt niet gehanteerd en heeft de verdachte die onvermogend is en aangewezen is op toegevoegde rechtsbijstand geen vrije advocatenkeuze.

\section{Processuele bevoegdheden}

Daarnaast zijn er waarborgen nodig die betrekking hebben op de wijze waarop door de raadsman namens de verdachte processuele bevoegdheden kunnen worden uitgeoefend, oftewel welke inhoud aan de rechtsbijstand kan worden gegeven. Hierbij gaat het bijvoorbeeld om het recht op informatie, toegang tot het dossier, het recht om verhoren, voorgeleidingen en zittingen bij te wonen en daarbij het woord te voeren, het recht om getuigen te ondervragen en om onderzoek te (laten) doen naar ontlastende feiten en omstandigheden. De raadsman zal moeten kunnen beschikken over dezelfde processuele bevoegdheden als de verdachte. Hierbij wordt uitdrukkelijk dezelfde bevoegdheden bedoeld en dus niet dat de raadsman méér bevoegdheden zou moeten hebben of bevoegdheden die de verdachte niet heeft. Dat zou immers in strijd komen met het uitgangspunt dat de verdachte in beginsel het recht heeft om zichzelf te verdedigen en dus primair degene is die ge-

50 CCBE Response to the Green Paper on Procedural safeguards for suspects and defendants in criminal proceedings throughout the European Union, 27 mei 2003. Zie voor de zorgwekkende situatie in de landen die binnenkort toetreden tot de EU: Access to Justice in Central and Eastern Europe, Comparative Report november 2002, gepresenteerd op het European Forum on Access to Justice 5-7 December 2002 in Boedapest, te vinden op de website <http://www.pili.org/library/access/country_reports.html>. 
bruik moet kunnen maken van zijn verdedigingsbevoegdheden, ook al heeft hij geen advocaat. ${ }^{51}$

Een bijzondere problematiek ten aanzien van het toekennen van processuele bevoegdheden speelt bij de verdediging bij verstek en is met name in Nederland België en Frankrijk gerezen. In deze landen is het mogelijk om verdachten bij verstek te veroordelen en anvankelijk werd het de advocaat niet toegestaan bij afwezigheid van de verdachte het woord ter verdediging te voeren. Deze praktijk werd door het EHRM in de zaken Poitrimol, Van Geyseghem en Lala en Pelladoah in strijd geacht met artikel 6 EVRM. ${ }^{52}$ In Nederland is daarop een regeling ingevoerd waarbij de raadsman zich door de verdachte kan laten machtigen om de verdediging namens hem te voeren en wordt vervolgens de procedure beschouwd als zijnde gevoerd op tegenspraak. Dit houdt tevens in en dat de beroepstermijnen korter zijn dan in de verstekprocedure waarbij vonnissen in veel gevallen eerst moeten worden betekend voordat de beroepstermijn gaat lopen en dat een uitspraak gemakkelijker is te executeren. ${ }^{53}$ In Frankrijk ligt momenteel een wetsvoorstel waarin een gelijksoortige constructie wordt voorgesteld ${ }^{54}$ en in België geldt eenzelfde op jurisprudentie gebaseerde praktijk. Op deze regelingen valt uit principieel oogpunt kritiek uit te oefenen om dat hierin van de fictie wordt uitgegaan dat aan de voorwaarden van een contradictoire procedure is voldaan indien de raadsman tot de verdediging wordt toegelaten. Hiermee wordt miskend dat alleen de aanwezigheid van de verdachte een contradictoire procedure mogelijk maakt, omdat de raadsman de verdachte nooit echt kan vervangen. Een ander negatief aspect van de machti-

51 EHRM 18 maart 1997, nr. 22209/93, Foucher, Reports 1997-II.

52 Frankrijk: EHRM 23 november 1993, Poitrimol, NJ 1994, 393; Nederland: EHRM 22 septe mber 1994, Pelladoah, NJ 1994, 733; EHRM 22 september 1994, Lala, 297-A; België: EHRM 21 januari 1999, Van Geyseghem, Reports 1999-I.

53 Zie voor een beschrijving van de wetsgeschiedenis en de kritiek op de regeling: T. Spronken, Verdediging.Een onderzoek naar de normering van het optreden van advocaten in strafzaken, Gouda Quint: Arnhem 2001, § 2.6.3-§ 2.6.5.

54 Zie art. 58 van het wetsvoorstel van 9 april 2003, ingediend door Raffarin en Perben. Dit voorstel ligt momenteel bij de Sénat en is al aangenomen door de Assemblee. 
gingsregeling is, dat hierdoor het aanwezigheidsrecht van de verdachte wordt verzwakt. Uit een recent in Nederland uitgevoerd onderzoek naar de werking van de verstekregeling blijkt dat de zittende magistratuur verzoeken tot aanhouding ter effectuering van het aanwezigheidsrecht wel eens afwijst vanwege de beperkte zittingscapaciteit en dat efficiency wat meer gewicht in de schaal lijkt te leggen, dan het belang van verdediging in aanwezigheid van de verdachte. ${ }^{55}$

De advocaat kan door de machtigingsconstructie voor problematische keuzen komen te staan, met name als overleg met zijn cliënt onmogelijk is. Er kunnen zich tijdens de behandeling van de zaak immers allerlei onvoorziene omstandigheden voordoen, die de advocaat niet met zijn cliënt heeft kunnen voorbereiden. De verstrekkende consequenties die zijn verbonden aan een behandeling op tegenspraak stellen de advocaat voor een ingewikkeld dilemma in het geval hij na de machtiging door zijn cliënt het contact met hem verliest: als hij niet verklaart tot de verdediging te zijn gemachtigd, dan mag hij geen verweer voeren ${ }^{56}$ als hij verklaart wel te zijn gemachtigd dan kan hij voor situaties komen te staan waarover hij met de cliënt geen overleg heeft gehad. De regeling lijkt niet in het leven te zijn geroepen om de kwaliteit van het onderzoek ter terechtzitting te verbeteren, maar met name om executiemogelijkheden te vergemakkelijken. Zo lang het mogelijk blijft om een verdachte bij verstek te veroordelen, valt niet in te zien waarom de raadsman niet bij verstek - dus zonder dat de fictie wordt gehanteerd van een contradictoire behandeling - de verdediging kan voeren. Dit is immers een verbetering van het contradictoire gehalte van de procedure ten opzichte van de situatie dat de raadsman bij verstek helemaal geen recht van spreken heeft. De raadsman moet bij verstek de verdediging kunnen voeren zonder dat daaraan voor de verdachte nadelige gevolgen worden verbonden. Naar mijn mening is het verbinden van nadelige

55 Zie het rapport: W.E.C.A. Valkenburg, P.D van Hees en P.A.W. Verboort, Evaluatie verstekregeling in strafzaken, Tilburg/'s-Gravenhage: Faculteit der Rechtsgeleerdheid/WODC 2002, te vinden op <www.wodc.nl>.

56 HR 23 april 2002, NJ 2002, 338. 
voorwaarden aan het kunnen uitoefenen van verdedigingsrechten in strijd met artikel 6 EVRM. ${ }^{57}$

\section{Vertrouwelijke communicatie}

Een elementaire voorwaarde voor effectieve rechtsbijstand is ook het recht op vertrouwelijke communicatie met de verdachte: het recht op vrij verkeer. Dat betekent dat er garanties moeten zijn dat de advocaat zijn cliënt vertrouwelijk kan bezoeken en spreken, zonder dat derden van de inhoud van het gesprek kunnen kennisnemen. Dat geldt ook voor de schriftelijke en telefonische communicatie. Bovendien moeten de contactmogelijkheden ruim genoeg zijn om de voorbereiding van de verdediging mogelijk te maken. ${ }^{58}$

Een met het vrij verkeer samenhangende garantie is dat de advocaat een verschoningsrecht moet hebben in die zin dat hij niet kan worden gedwongen om hetgeen aan hem in het kader van de verdediging ter kennis is gekomen prijs te geven. Dat betekent niet alleen dat een advocaat als getuige niet kan worden gedwongen om over vertrouwelijke informatie te verklaren, maar ook dat er adequate maatregelen moeten worden getroffen dat vertrouwelijke informatie niet door middel van het toepassen van opsporingsmethoden zoals bijvoorbeeld het afluisteren van telefoonverkeer ter kennis van de justitiële instanties komt. In dit verband zijn er zorgelijke ontwikkelingen te constateren. Zo ligt er in Frankrijk een wetsvoorstel dat het mogelijk maakt dat door justitie uitlevering van documenten wordt gevraagd zonder

57 Zie in dit verband EHRM 13 februari 2001, Krombach tegen Frankrijk, EHRC 2001, 22 waarin het kunnen instellen van een rechtsmiddel werd verbonden aan de voorwaarde dat de verdachte zich zou melden en laten arresteren. Naar aanleiding hiervan overweegt het EHRM:' § 87 On the other hand, there can be no question of an accused being obliged to surrender to custody in order to secure the right to be retried in conditions that comply with Article 6 of the Convention, for that would entail making the exercise of the right to a fair hearing conditional on the accused offering up his or her physical liberty as a form of guarantee. In dezelfde zin: EHRM 16 mei 2002, Karatas en Sari tegen Frankrijk, EHRC 2002, 51.

58 EHRM 12-03-2003, Öcalan tegen Turkije, EHRC 2003, 38. 
dat er een beroep op geheimhouding kan worden gedaan. ${ }^{59}$ In Nederland kunnen sinds de invoering van de Wet bijzondere opsporingsbevoegdheden per 1 februari $2000^{60}$ opsporingsbevoegdheden, zoals het onder observatie houden, het afluisteren van telefoonverkeer, het direct afluisteren of het inzetten van informanten en infiltranten, ook tegen advocaten worden ingezet, ook al zijn deze geen verdachten. Daardoor kunnen vertrouwelijke gegevens ter kennis komen van justitie, zonder dat de advocaat daar weet van heeft. Weliswaar behoren gegevens die onder het verschoningsrecht van de advocaat vallen door de officier van justitie onmiddellijk te worden vernietigd, maar in de praktijk is gebleken dat deze verplichting structureel niet wordt nageleefd. ${ }^{61}$

Met het oog op deze ontwikkelingen dient de procedurele bescherming van het beroepsgeheim beter te worden geregeld. Inbeslagnemingsbevoegdheden mogen zich niet uitstrekken tot vertrouwelijke gegevens van professionele geheimhouders. De schifting tussen vertrouwelijke en niet-vertrouwelijke gegevens, dient te geschieden door een rechter in samenspraak met een onafhankelijke advocaat, zoals bijvoorbeeld de deken van de orde van advocaten. ${ }^{62}$ Ten aanzien van de hiervoor genoemde opsporingsbevoegdheden zoals observeren, afluisteren en infiltreren zou moeten worden gegarandeerd dat deze niet gericht mogen worden ingezet tegen professionele geheimhouders zoals advocaten. Het is een absurde situatie dat in Nederland thans de doorzoeking van een advocatenkantoor slechts door een rechter mag geschieden en met allerlei waarborgen is omkleed om te voorkomen dat het beroepsgeheim wordt geschonden, en dat bijvoorbeeld het afluisteren van de telefoonaansluitingen van een advocatenkantoor of het plaatsen van afluisterapparatuur in een advocatenkantoor wel mogelijk is. Een vernietigingsplicht achteraf, en dan

59 Zie art.28 van het wetsvoorstel van 9 april 2003, ingediend door Raffarin en Perben. Dit voorstel ligt momenteel bij de Sénat en is al aangenomen door de Assemblee.

60 Wet van 27 mei 1999, Stb. 1999, 245.

61 Zie voor een bespreking van deze problematiek T. Spronken, De privileges van de raadsman, in: T. Prakken en T. Spronken (red.), Handboek verdediging, Deventer: Kluwer 2003, hoofdstuk 2, § 4.2.17.

62 EHRM 16 december 1992, Niemietz, NJ 1993, 400. 
ook nog door de officier van justitie nadat deze van de inhoud heeft kennisgenomen, kan onmogelijk als afdoende bescherming van het verschoningsrecht worden aangemerkt. ${ }^{63}$

Ook de vernietiging van geheimhoudersgegevens die door de toepassing van opsporingsbevoegdheden op verdachten ter kennis van justitie komen moet worden geregeld.

Voornoemde waarborgen dienen in de wetgeving te worden verankerd en niet te worden overgelaten aan wisselende plaatselijke of nationale gbruiken. Zeker indien de grenzen binnen de EU geen obstakels meer vormen voor de toepassing van dit soort zeer in de privacy ingrijpende opsporingsbevoegdheden dient er een regeling op Europees niveau te komen waarbij het verschoningsrecht wordt beschermd.

\section{Vrijheid van verdediging}

Tot slot moet ook de vrijheid van verdediging worden gewaarborgd in die zin dat de advocaat in beginsel alles ter verdediging kan aanvoeren wat hem dienstig voorkomt. Raadslieden dienen niet te worden beschouwd als verlengstukken van hun (criminele) cliënten en het verlenen van legitieme rechtsbijstand mag niet worden gecriminaliseerd. Dit lijkt vanzelfsprekend maar is het in de praktijk niet. Recentelijk is het zowel in Nederland als in Duitsland voorgekomen dat advocaten werden gearresteerd terwijl zij rechtsbijstand verleenden. In Nederland gebeurde dit toen advocaten weigerden hun cliënt, die dreigde onrechtmatig te worden uitgeleverd, te verlaten. Daarbij werden de advocaten door de arrestatie feitelijk belemmerd om nog rechtsmiddelen ten behoeve van hun cliënt aan te wenden en werd hen bezoek van advocaten die hen wilden bijstaan geweigerd. ${ }^{64}$ In Duitsland werd een advocaat gearresteerd op de zitting toen hij akte vroeg van de mededeling van de rechter dat hij de verdachte eigenlijk in vrijheid had moeten stellen, maar dit gelet op de toon

63 Tot deze conclusie komt ook het College Bescherming Persoonsgegevens in zijn rapport Onderzoek naar de waarborging van de vertrouwelijke communicatie van advocaten bij de interceptie van telecommunicatie d.d. 17 juli 2003, te raadplegen op <www.cbpweb.nl>.

64 T. Spronken, Arrestatie van advocaten Mullah Krekar, NbSr 2003, p. 101-103. 
waarop het verzoek tot invrijheidstelling door de advocaat was gedaan, afwees. ${ }^{65}$ Indien de justitiële autoriteiten van oordeel zijn dat advocaten bij hun verdediging over de schreef gaan, dan dienen zij hiertoe een tuchtrechtelijke procedure te volgen en niet een strafrechtelijke vervolging in te stellen.

In dit verband kan verwezen worden naar een aantal internationale regelingen waarin beoogd wordt advocaten te beschermen tegen vervolging voor activiteiten die zij in het kader van een legitieme verdediging en conform hun eigen gedragsregels verrichten.

In de eerste plaats kan worden gewezen op de Basic Principles on the Role of Lawyers van de VN, ook wel de Havana Principles genoemd, waarin de verplichting van de overheid is vastgelegd de onafhankelijkheid van de advocatuur te waarborgen. Volgens de Havana Principles mogen advocaten niet het slachtoffer worden van, of worden bedreigd met, strafrechtelijke vervolging of andere sancties indien zij hun werk verrichten overeenkomstig de voor de beroepsuitoefening erkende maatstaven en gedragsnormen. Met name mogen advocaten niet worden vereenzelvigd met de cliënt als gevolg van het vervullen van hun taak en moeten zij worden gevrijwaard van strafvervolging met betrekking tot uitlatingen die te goeder trouw in rechte worden gedaan. ${ }^{66}$

65 Strafverteidiger im Sitzungssaal in Ausübung seines Berufs verhaftet, Presseerklärung $\begin{array}{lllll}\text { Strafverteidigervereinigung } & \text { NRW, } & \text { Essen } & & \end{array}$ <www.strafverteidigervereinigungen.org>.

66 Basic Principles on the Role of Lawyers van de VN, aanvaard op the Eight Crime Congress, Havana 7 September 1990, bekrachtigd door Resolutie 45/121 van de Algemene Vergadering van de VN d.d. 14 december 1990. Zie ook Aanbeveling no. (2000) 21 van het Comité van Ministers van de Raad van Europa waarin de regeringen van de lidstaten wordt aanbevolen alle maatregelen te nemen om de vrijheid van het beroep van advocaat te garanderen en waarin bijvoorbeeld staat: 'lawyers should not suffer or be threatened with any sanctions or pressure when acting in accordance with their professional standards'. Weliswaar is het EHRM van oordeel dat aan de vrijheid van meningsuiting, gelet op de bijzondere positie die de advocaat inneemt in de rechtspleging, kan worden beperkt, EHRM 20 mei 1998, Schöpfer, Reports 1998-II, in de zaak Nikula v. Finland (EHRM 21 maart 2002, nr. 31611/96) overweegt het EHRM: 'Even so, the threat of an ex post facto review of counsel's criticism of another party to criminal proceedings - which the public prosecutor doubtless must be considered to be - is difficult to reconcile with 


\section{Verplichtingen van de strafrechtadvocaat}

Ook al biedt het strafproces alle faciliteiten en waarborgen om effectieve rechtsbijstand mogelijk te maken, deze blijven een dode letter als de advocaat daar geen invulling aan geeft.

\section{Vertrouwensrelatie en vrije advocatenkeuze}

De advocaat moet zich inspannen voor het ontstaan en de instandhouding van een vertrouwensrelatie met de verdachte en dient zorgvuldig met die vertrouwensrelatie om te gaan. Hij moet met de verdachte overleggen over de verdedigingsstrategie en het staat de raadsman niet vrij de verdediging te voeren op een wijze die strijdig is met de wil van de verdachte.

Indien een verschil van mening of inzicht tussen raadsman en verdachte leidt tot een breuk in de vertrouwensrelatie, dient de raadsman zich terug te trekken en moet hij er zorg voor dragen dat de verdachte daarvan zo min mogelijk nadeel ondervindt.

De advocaat zal ook de vrije advocatenkeuze van de verdachte moeten respecteren en hem niet tegen zijn wil mogen bijstaan.

\section{Geheimhoudingsplicht}

Van groot belang is ook dat de advocaat tot geheimhouding verplicht is van alles wat hem in het kader van de rechtsbijstand ter kennis komt. Dit strekt verder dan alleen de mededelingen die de verdachte hem doet en omvat ook de informatie die de raadsman in het kader van de verdediging van derden ontvangt. Alleen als een juiste uitvoering van de aan hem opgedragen taak een gebruik maken van zijn verkregen kennis tegenover derden eist, staat dat de raadsman vrij, voorzover de ver-

\footnotetext{
defence counsel's duty to defend their clients' interests zealously. It follows that it should be primarily for counsel themselves, subject to supervision by the bench, to assess the relevance and usefulness of a defence argument without being influenced by the potential "chilling effect" of even a relatively light criminal sanction or an obligation to pay compensation for harm suffered or costs incurred'.
} 
dachte daartegen geen bezwaar heeft en voorzover dit in overeenstemming is met een goede beroepsuitoefening.

In dat verband is de invoering van een meldplicht voor advocaten bij ongebruikelijke transacties een gevoelige slag voor het recht van de burger op juridisch advies. ${ }^{67}$ Door deze meldplicht wordt de rechtstatelijke rol van de advocaat bedreigd. Ook al is de meldplicht beperkt tot advieswerkzaamheden die verband (kunnen) houden met witwasactiviteiten, de psychologische drempel is overschreden. De meldplicht leidt tot rolvervaging en -verwarring. De advocaat dient uit hoofde van zijn functie niet te worden ingezet voor de opsporing van strafbare feiten.

\section{Verbod van behartigen van tegenstrijdige belangen}

Om de partijdigheid, onafhankelijkheid en het beroepsgeheim te waarborgen is het de advocaat verboden tegenstrijdige belangen te behartigen. Dit verbod, dat in alle gedragscodes voor advocaten voorkomt, heeft een civiele oorsprong omdat het verbod vaak gedefinieerd wordt als een verbod om de belangen van twee of meer partijen te behartigen. In strafzaken speelt dit vooral bij het behartigen van de belangen van meer verdachten in één zaak, waarbij de verdachten onderling tegenstrijdige belangen kunnen hebben. Het verbod van behartiging van tegenstrijdige belangen heeft echter een verdergaande strekking: de advocaat dient zich niet in een positie te plaatsen waarin hij niet meer vrij is om zich uitsluitend te richten op de belangenbehartiging van zijn cliënt. ${ }^{68}$ Dit kan veroorzaakt worden door tegen-

67 Richtlijn 2001/97/EG van het Europees Parlement en de Raad van 4 december 2001 tot wijziging van de Richtlijn 91/308/EEG van de Raad tot voorkoming van het gebruik van het financiële stelsel voor het witwassen van geld, PbEG L 344 van 28.12.2001, p. 76. Zie voor een bespreking hiervan T. Spronken, 'De Europese Witwasrichtlijn en de erosie van het verschoningsrecht', in: Iets Bijzonders: Liber Amicorum aangeboden aan Mischa Wladimiroff ter gelege nheid van zijn 30-jarig jubileum als advocaat, Den Haag: SDU Uitgevers 2002.

68 Zie de General Principles for Ethics of Lawyers van de International Bar Association (IBA): 'Lawyers shall not place themselves in a position in which their clients' interests conflict with those of themselves, their partners or another client'. 
strijdige belangen van verschillende cliënten of door tegenstrijdige belangen tussen de verdachte en de advocaat zelf. ${ }^{69}$

Tot zo ver de uitgangspunten die mijns inziens in aanmerking komen om te worden vastgelegd in een Europees Statuut voor de strafrechtadvocaat.

\section{Grensoverschrijdende rechtsbijstand}

De slotvraag die rijst is of een Europees statuut voor de strafrechtadvocaat ook een oplossing kan bieden voor de problemen waar de advocaat voor kan komen te staan als hij betrokken wordt bij de verdediging van een verdachte in een andere EUlidstaat dan waar hij gevestigd is.

Advocaten uit de EU-lidstaten kunnen in andere lidstaten optreden of zich daar onder eigen titel vestigen. ${ }^{70}$ In beide gevallen zijn de advocaten voor de uitoefening van werkzaamheden, waarvoor de hoedanigheid van advocaat vereist is en waarbij sprake is van vertegenwoordiging in rechte, verplicht tot samenwerking met een advocaat in het gastland. Uitgangspunt voor de bezoekende advocaat is dat de advocaat in het gastland de daar geldende beroepsregels in acht dient te nemen, terwijl hij ook gebonden blijft aan de beroepsregels van zijn eigen land. De advocaat die in het gastland optreedt kan ook onderworpen worden aan de tuchtrechtspraak van het gastland. ${ }^{71}$ Wat de verplichting tot samenwerking inhoudt heeft het Hof van

69 Dit kan zich bijvoorbeeld voordoen als de advocaat in dezelfde strafzaak als zijn cliënt als verdachte wordt beschouwd.

70 Dit is geregeld in de Richtlijn van de Raad van 22 maart 1977 tot vergemakkelijking van de daadwerkelijke door advocaten van het vrij verkeer van diensten, 77/249/EG, Pb. L 78; de EGRichtlijn diploma erkenning, 89/48/EEG van 21 december 1988, Pb. L 019 en Vestigingsrichtlijn voor advocaten van 16 februari 1998. 98/5/EG.

71 De regeling is in detail gecompliceerder dan hier staat aangegeven en kan - omdat art. 7 lid 2 van de Richtlijn 77/249/EG daartoe de lidstaten een eigen bevoegdheid geeft - ook van land tot land verschillen. Zo wordt er in Nederland voor de toepasselijkheid van de beroepsregels onderscheid gemaakt al naar gelang de soort werkzaamheden die worden verricht en of de advocaat al 
Justitie in 1988 bepaald in een zaak tegen de Bondsrepubliek Duitsland. ${ }^{72}$ De plaatselijke advocaat dient de bezoekende advocaat de nodige ondersteuning te bieden bij het optreden in een ander rechtsstelsel dan het zijne. Advocaten moeten zelf, met inachtneming van de geldende beroepsregels en zelfstandig hun samenwerking in een vorm gieten die in overeenstemming is met hun mandaat. Lidstaten kunnen regels voor de samenwerking vaststellen, maar die mogen niet zo ver gaan dat wordt geëist dat alleen de nationale advocaat in rechte mag optreden of dat een advocaat uit een andere lidstaat alleen vergezeld van de plaatselijke advocaat ter zitting mag verschijnen. Ook mogen er geen ongerechtvaardigde regels worden gsteld aan het bewijs van de samenwerking in die zin dat dit ten aanzien van iedere handeling zou moeten worden aangetoond. Voor wat betreft het bezoeken van gdetineerde cliënten mag bovendien niet worden geëist dat de bezoekende advocaat de cliënt alleen mag bezoeken in gezelschap van de plaatselijke advocaat of dat de correspondentie met een gedetineerde cliënt alleen via de plaatselijke advocaat mag verlopen.

Dit is in een notendop de regeling die geldt voor het optreden buiten eigen landsgrenzen. Deze biedt op geen enkele wijze oplossingen hoe in de praktijk moet worden omgegaan met conflicterende beroepsregels in gevallen waarbij de rechtsbijstand zowel in het thuisland als in het gastland wordt verleend.

Hoe moet bijvoorbeeld een Nederlandse advocaat, die geen officer of the court is zoals zijn collega in Engeland omgaan met het verbod het gerecht te misleiden in een situatie waarin zijn Nederlandse cliënt, toen hij zich in Nederland bevond tegenover hem heeft bekend maar inmiddels overgeleverd naar Engeland daar in rechte wil ontkennen? De gedragsregels voor solicitors en barristers in Engeland verbieden in een dergelijk geval een verdedigingsstrategie te voeren die niet in

dan niet onder zijn eigen titel ingeschreven is. Zie voor een overzichtelijke bespreking van de Nederlandse situatie F. Orie, Het Nederlandse tuchtrecht, in Recht op tuchtrecht, 50 jaar Hof van Discipline, 2003, p. 196-207.

72 HvJ EG 25 februari 1988, zaak 427/85, NJ 1990, 22. 
overeenstemming is met de bekentenis. ${ }^{73}$ Moet de Nederlandse advocaat, als hij zijn cliënt ook in Engeland in rechte wil bijstaan, deze bekentenis dan maar voor zijn Britse collega verzwijgen?

In België is het verboden dat de advocaat voorafgaand aan de zitting contact heeft met welke getuige dan ook. Hoe moet de samenwerking verlopen met een advocaat uit een andere lidstaat waar deze belemmering niet geldt en die in het kader van de voorbereiding van een getuigenverhoor in België al uitgebreid vanuit zijn eigen land telefonisch met de getuige heeft gesproken?

Indien zowel het onderzoek als de berechting van een strafzaak zich in één lidstaat afspeelt, zal als regel gelden dat de beroepsregels van desbetreffende lidstaat ook van toepassing zijn op de bezoekende advocaat. Deze regel biedt echter geen oplossing als bijstand moet worden verleend in verschillende landen waar verschillende beroepsregels gelden. Voor dit soort situaties zijn geen gemakkelijke oplossingen te bedenken. Gelet op de verwevenheid van beroepsregels met nationale strafprocessuele systemen valt ook van een harmonisering van gedragscodes, die onlangs door de Europese Commissie is afgekondigd, ${ }^{74}$ geen oplossing te verwachten, zo lang iedere lidstaat op het gebied van het strafrecht zijn eigen identiteit blijft behouden.

73 In de Code of Conduct of the Bar of England and Wales is bijvoorbeeld bepaald ten aanzien van confessions of guilt: 'It follows that the mere fact that a person charged with a crime has confessed to his counsel that he did commit the offence charged is no bar to that barrister appearing or continuing to appear in his defence, nor indeed dows such a confession release the barrister from his imperative duty to do all that he honourably can for his client. [...] Such a confession, however, imposes very strict limitations on the conduct of the defence. A barrister must not assert as true that which he knows to be false. He must not connive at, much less attempt to substantiate, a fraud [...] He must not set up an affirmative case inconsistent with the confession made to him'.

74 Persbericht van de Europese Commissie naar aanleiding van de Interne Markt Strategie 20032006 van 7 mei 2003, waarin verwezen wordt naar een voorstel van de Europese Commissie om voor het einde van 2003 te komen tot een richtlijn tot vergemakkelijking van grensoverschrijdende dienstverlening. In deze context is de Europese Commissie van oordeel dat er een noodzaak bestaat tot afstemming - zo nodig harmonisatie - van gedragsregels op Europees niveau. 
Een statuut zoals door mij voorgestaan kan daarvoor geen oplossingen bieden en is daarvoor ook niet bedoeld.

Dit laat echter onverlet dat het aanvaarden en expliciteren van gemeenschappelijke uitgangspunten kan aanzetten tot het kritisch bezien van eigen gedragscodes die vaak gestoeld zijn op tradities zonder dat men zich heeft afgevraagd in hoeverre deze bijdragen aan een adequate verdediging in strafzaken. Daarbij kunnen gedragscodes ook worden getoetst aan de uitgangspunten die in het EVRM en de jurisprudentie van het EHRM ten grondslag zijn gelegd aan een effectieve verdediging. Om met de hiervoor genoemde voorbeelden af te sluiten: ik vraag mij af of het verbod voor de Belgische advocaat om voor de zitting geen enkel contact te onderhouden met getuigen zich wel verdraagt met het beginsel van equality of arms, als de politie en het OM deze bevoegdheden wel heeft. Is het wel in overeenstemming met de vrijheid van de verdachte om zijn eigen procespositie te bepalen en zijn verdediging te voeren c.q. het nemo tenetur-beginsel, dat een advocaat tegenover wie de cliënt in vertrouwen heeft verteld dat hij schuldig is, niet meer in volle omvang de verdediging mag voeren indien de cliënt in rechte stelt onschuldig te zijn, zoals in Engeland het geval is?

Ik ben gekomen aan het einde van mijn verhaal, beseffend dat ik wellicht meer vragen heb opgeworpen dan beantwoord. Er valt dan ook nog veel te onderzoeken. Ik hoop in ieder geval dat ik vandaag heb overgebracht dat criminaliteitsbestrijding onlosmakelijk verbonden dient te zijn met adequate rechtsbescherming als wij willen streven naar een 'place of greater safety'. Niets is immers onveiliger dan een overheid waartegen je je niet kunt verweren. 


\section{Slotwoord}

In een tijd waarin crime-control het beeld bepaalt, is het een goede zaak dat er een leerstoel wordt ingesteld die zich toelegt op onderzoek naar en ten behoeve van de verdediging in strafzaken. Ik voel mij bijzonder vereerd dat de Nederlandse Vereniging van Strafrechtadvocaten en de juridische faculteit mij verzocht hebben om deze leerstoel te bekleden en hoop dat ik het in mij gestelde vertrouwen waar kan maken. Voor mij betekent deze benoeming dat ik kan voortgaan op het gebied waar mijn hart ligt. En dat is een groot voorrecht.

Ook de facultaire gemeenschap wil ik bedanken voor de collegialiteit die ik - in de afgelopen zestien jaren dat ik er inmiddels werkzaam ben - genoten heb, met name van mijn collega's bij de Advocatenpraktijk Universiteit Maastricht en de Capaciteitsgroep strafrecht en criminologie. In het bijzonder wil ik daarbij noemen Gerard Mols, vanaf het prille begin van onze start in de advocatuur mijn brother in arms in veel grote strafzaken en ook daarbuiten en Ties Prakken die, al voordat ik haar persoonlijk zo goed kende als nu het geval is, mij bijzonder heeft geïnspireerd met haar opvattingen over de verdediging in strafzaken en met wie ik hoop nog lang te kunnen samenwerken.

Het onderwijs in de Maastrichtse faculteit is probleemgestuurd en het onderwijs dat gegeven wordt in de Advocatenpraktijk Universiteit Maastricht is dat in het kwadraat. De samenwerking met studenten aan echte zaken is leerzaam voor alle betrokkenen en ik hoop dat dergelijke onderwijsvormen de druk van de huidige bezuinigingsdrang kunnen weerstaan. Met name binnen de Advocatenpraktijk kunnen studenten ervaren dat het in het recht uiteindelijk om mensen gaat, die begrip en respect verdienen in welke positie zij zich ook bevinden of wat zij ook gedaan hebben.

Wies Rayar en Marjo Mullers wil ik bedanken voor respectievelijk de vertaling van deze rede in het Engels en de opmaak van de gedrukte versie ervan.

Tot slot dank ik Gijs, Kai en Michiel, zonder wie ik mij mijn leven niet kan voorstellen en die er altijd voor zorgen dat ik met beide benen op de grond blijf staan. 


\section{'A place of greater safety'}

Reflections on a European Charter for Criminal Defence Lawyers

Inaugural Lecture delivered on the occasion of acceptance of the chair of professor extraordinary of criminal defence at Maastricht University, on Friday 10 October 2003

by

Taru Spronken

This inaugural lecture has been given the title of Hilary Mantel's novel, A Place of Greater Safety, Penguin Books (1993). The novel deals with the French Revolution and the fortunes of its famous protagonists, Danton, Lacroix, Desmoulins and Robespierre. In spite of the revolutionary slogan 'liberté, égalité et fraterité', they were executed with effectually no form of process in the aftermath of the revolution.

Layout by Marjo Mullers

Translated from the Dutch by Louise Rayar 
ISBN: 9013008496

(C) 2003, T. Spronken

Copyright tekst 
Esteemed Rector,

Ladies and Gentlemen,

\section{Introduction}

Developments in the area of cooperation in criminal matters within the European Union present criminal defence lawyers with new challenges. Although for some time larger-scale criminal investigations have not stopped at national borders, the majority of criminal defence lawyers has virtually no knowledge of practical criminal procedure abroad. Inasmuch as cooperation in criminal matters within the EU is nowadays given shape through mutual recognition of decisions by public prosecutors and judges, lawyers will increasingly be confronted with legal orders, in which diverse substantive and procedural rules apply. As transnational police and judicial powers are widened, suspects and accused will be more and more the subject of investigative and prosecutorial acts outside their own country and there will be a growing need for transnational legal assistance. Where investigation and prosecution transgress borders, lawyers from different countries will have to work together, the defence will have to be coordinated and the demand for information about other member states' rules of evidence and procedure will intensify.

However, this is not all that calls for reflection. The various national criminal procedures are deeply rooted in historical and cultural traditions, which are reflected in the organisation and the practice of the profession of lawyer as well. Perceptions of the role and duties of criminal defence lawyers are closely related to the criminal procedures within which these lawyers operate. In the event of crossborder defence, lawyers will encounter different, at times conflicting, codes of conduct and perceptions of professionals practice. Green Papers have been published on the establishment of a European Prosecutor and on Procedural Safeguards for Suspects 
and Defendants in Criminal Proceedings throughout the European Union, ${ }^{1}$ but what about the need for European criminal lawyers to reflect on a common position with regard to the conditions for effective defence and how they perceive their role and duties in such defence? Why not lay these views down in a European Charter for Criminal Defence Lawyers? Before addressing these questions, I will first discuss those developments within the EU that form the context of future criminal defence.

\section{2. 'A Place of Greater Safety'}

Ever since the Treaty of Amsterdam, the EU has aspired to provide European citizens with a 'high level of security' and an 'area of freedom, security and justice'. ${ }^{2}$ The Action Plan of the Council and the Commission of 3 December $1998,{ }^{3}$ in which this objective is further defined, shows that freedom, security and justice are mainly perceived as being safe from crime. In the Action Plan:

- freedom is defined as: 'to live in a law-abiding environment in the knowledge that public authorities are using everything in their individual and collective power $[\ldots]$ to combat and contain those who seek to deny or abuse that freedom';

1 Green Paper on criminatlaw protection of the financial interests of the Community and the establishment of a European Prosecutor, 11 December 2001 COM (2001) 715 final; Green Paper Procedural Safeguards for Suspects and Defendants in Criminal Proceedings throughout the European Union, 19 February 2003 COM (2003) 75.

2 Treaty of Amsterdam amending the Treaty on European Union, the Treaties establishing the European Communities and certain related acts, signed at Amsterdam, 2 October 1997, OJ 1997 C 340/1. See for a comment on the Treaty's impact on criminal law the inaugural lecture by A.H.J. Swart, Een ware Europese rechtsruimte, (Deventer, Gouda Quint 2001); A.H. Klip, Amsterdams Uniestrafrecht, NJB (1998), pp. 711-716 and G.J.M. Corstens, 'Strafrechtspleging na het Verdrag van Amsterdam', NJB (1998), pp. 804-808.

3 Action Plan of the Council and the Commission on how best to implement the provisions of the Treaty of Amsterdam on an area of freedom, security and justice. Text adopted by the Justice and Home Affairs Council of 3 December 1998, OJ 1999 C 19/1. 
- security is achieved through 'common action among the Member States in the indissociable fields of police cooperation and judicial cooperation in criminal matters and thus not only to offer enhanced security to their citizens but also to defend the Union's interests, including its financial interests' [...] 'In concrete terms this means first of all that criminal behaviour should be approached in an equally efficient way throughout the Union: terrorism, corruption, traffic in human beings, organised crime, should be the subject of minimum common rules relating to the constituent elements of criminal acts, and should be pursued with the same vigour wherever they take place'; and

- justice 'must be seen as facilitating the day-to-day life of people and bringing to justice those who threaten the freedom and security of individuals and society'.

\section{The Marginalisation of Legal Protection}

Leaving aside rather general references on respect for individual rights and the applicability of the European Convention of Human Rights (ECHR), ${ }^{4}$ freedom and justice, in the sense of legal protection against (Community) authorities and the right to a fair trial is, have received virtually no attention in the criminal law of the Union. ${ }^{5}$ The Action Plan, which contains very detailed and comprehensive schemes for police and judicial cooperation, is very vague on legal protection and procedural guarantees:

4 See, for instance, Article 6 of the Treaty on European Union, consolidated version of 24 December 2002, OJ 2002 C 324/5, which entered into force in February 2003; Communication from the Commission of 14 July 1998 'Towards an area of freedom, security and justice' COM (1998) 459 final; Programme of measures to implement the principle of mutual recognition of decisions in criminal matters, OJ $2001 \mathrm{C} 12 / 10$; Green Paper on criminatlaw protection of the financial interests of the Community and the establishment of a European Prosecutor, 11 December 2001 COM (2001) 715 final.

5 See also A.H. Klip, 'Unistrafrecht is op hol geslagen', $N J B$ (1997), p. 667. 
'Procedural rules should respond to broadly the same guarantees, ensuring that people will not be treated unevenly according to the jurisdiction dealing with their case. In principle, this function of adequate and comparable procedural guarantees is already achieved by the safeguards of the European Convention on Human Rights and Fundamental Freedoms and their dynamic interpretation by the European Court of Human Rights, in particular regarding the rights of the defence in criminal proceedings. It appears useful, however, to complement those basic principles by standards and codes of good practice in areas of transnational relevance and common concern'.

\section{$[\ldots]$}

'Difficulties with which citizens are intrinsically confronted in crossborder litigation, be it in civil or in criminal matters, should be neutralised as much as possible. This means, for example, streamlined communication of documents and information, use of multilingual forms, creation of mechanisms or networks to assist and advise in transnational cases and possible legal aid schemes'.

\section{$[\ldots]$}

'Efficient procedural standards should be sought that will improve mutual assistance in criminal matters while complying with the requirements of fundamental freedoms'.

Meanwhile, cooperation between EU member states in criminal matters is pursued energetically, driven mainly by the desire to control crime. ${ }^{7}$ In addition to the 
Framework decisions aimed at approximating the rules governing, for instance, drug trafficking, traffic in human beings, the sexual exploitation of children and child pornography, racism, money laundering and, yes, terrorism, measures have also been taken to facilitate mutual assistance through mutual recognition of national decisions in criminal cases. The Draft Treaty establishing a Constitution for Europe of 20 June 2003 goes even beyond this and contains provisions aimed at harmonising substantive and procedural criminal law. ${ }^{8}$

The most tangible example of such cooperation is the European arrest warrant, which will come into effect on 1 January 2004 for all fifteen EU member states, replacing existing extradition procedures. ${ }^{9}$ In future, arrest warrants issued by the one member state, as a result of conviction or suspicion, will have to be respected unconditionally by the other member state. Apart from a limited number of grounds for refusing execution, most of which are optional, each member state is obliged to arrest and surrender the wanted person, with the inclusion of its own subjects, without examining first whether prosecution and trial for that particular offence are in conformity with its own domestic norms and values. ${ }^{10}$ Under the European arrest warrant, the requirement that the offence must also constitute a criminal offence in the other member state has been revoked for the categories of offences listed in the Framework Decision. Offences punishable under domestic law may be prosecuted throughout the European Union. ${ }^{11}$

7 See more comprehensively G.J.M Corstens and M.I. Veldt-Foglia, Communautarisering van het straf-en strafprocesrecht, Ontwikkelingen en grenzen, Preadvies voor de Vereniging voor de vergelijkende studie van het recht van België en Nederland, (DD, 2003), pp. 103-177.

8 Draft Treaty establishing a Constitution for Europe, 20 June 2003 CONV 820/03; see in this context G.J.M. Corstens, 'Het einde van het nationale strafrecht?', NJB (2003), pp. 1429-1430.

9 Council Framework Decision of 13 June 2002 on the European arrest warrant and the surrender procedures between Member States, OJ 2002 L 190/1.

10 See for a structured discussion of the European Arrest Warrant and the non-execution grounds, A. Smeulers, 'Het Europees aanhoudingsbevel', MRT (July/August 2003).

11 See Article 2 Council Framework Decision on the European arrest warrant. 
Since legal safeguards often negatively affect smooth interstate cooperation, the easing of European cooperation in criminal matters, of which the European arrest warrant is an example, comes with the dismantling of these safeguards for citizens and alleged offenders. This is deemed justified, because the EU member states have great faith in each other's criminal justice systems. This is based on the assumption that there are equivalent levels of legal protection in the EU. Whether such faith is warranted is a matter of debate. From the inventory made by Smeulers and de Vries it can be inferred that in nearly half of the present and future EU member states troubling to very troubling human rights situations have been found to exist. ${ }^{12}$ Problems range from discrimination and racism by police forces, physical abuse at police stations and substandard conditions of detention to protracted proceedings and no direct access to legal assistance. ${ }^{13}$

Furthermore, the national legal systems within the EU are very diverse and each member state has its own interpretation of the obligations imposed on it by the European Convention. As a result, the level of legal protection varies considerably from state to state. Safeguards pertaining to criminal procedure are interpreted differently in Common Law countries, where proceedings are of a more accusatorial nature, than in Civil Law countries, whose systems are rather more inquisitorial. ${ }^{14}$ There are large differences between these two types of system as to the length of criminal proceedings, the application of preliminary detention, admissibility of (anonymous) evidence, the possibilities of trials in absentia, eligibility for legal aid

12 A. Smeulers and J. de Vries, 'Het Europees aanhoudingsbevel: gerechtvaardigd vertrouwen?', NJCM-Bulletin (2003), pp. 428-460.

13 See for defects of legal assistance in criminal cases in countries which will shortly accede to the EU also: Access to Justice in Central and Eastern Europe, Comparative Report (November 2002), presented at the European Forum on Access to Justice 5-7 December 2002 in Budapest, source: <http://www.pili.org/library/access/country_reports.html>.

14 See for the differences with the Nordic states, Norway, Denmark, Sweden and Finland: M. Boerlage and C.F. Mulder, 'Europa, het strafrecht en de rafelige noordgrens van de Europese Unie', $D D$ (2003), pp. 726-744. 
and the right to be assisted by counsel during preliminary investigation. ${ }^{15}$ It is no coincidence that the European heads of government, gathered at the Tampere summit in October 1999, concluded that mutual recognition of judicial decisions, viewed as the cornerstone of judicial cooperation within the European Union, should go hand in hand with the establishment of common minimal standards applying to criminal procedure. ${ }^{16}$

\section{The Green Paper on Procedural Safeguards}

In order to meet the criticism that repressive measures within the EU are not flanked by measures in the area of legal protection, on 19 February 2003, the Commission presented a Green Paper on Procedural Safeguards for Suspects and Defendants in Criminal Proceedings throughout the European Union. I will refer to it from here on as the Green Paper on Procedural Safeguards. ${ }^{17}$ The Paper fails to deliver what its title promises. It discusses five aspects, important in themselves, of legal protection: the right to legal assistance and interpreters; the right to translation; the accused's right to information; the protection of vulnerable groups; and consular assistance. Other major topics pertaining to criminal proceedings, such as admissibility of evidence; the right to silence; the presumption of innocence; the right of access to the case file; the obligation to disclose disculpatory evidence; the prohibition against double jeopardy; the right to examine witnesses, release on bail;

15 For a very illustrative case-study on the diverse appreciation of evidence in the United Kin gdom, Germany and France: Analysis of the Green Paper on criminallaw protection of the financial interests of the Community and the establishment of a European Prosecutor, Study commissioned by the Committee on Budgets of the European Parliament by Anke Biehler, Dr Sabine Gleß, Nina Parra, Dr Helge Elisabeth Zeitler, Max Planck Institute of Foreign and International Criminal Law, Freiburg/Br. (April 2002), pp. 38-46.

16 Commission of the European Communities, Presidency Conclusions, Tampere European Council 15 and 16 October 1999, SI (1999) 800, summarised in NJB (1999), pp. 1831-1833.

17 Green Paper Procedural Safeguards for Suspects and Defendants in Criminal Proceedings throughout the European Union, 19 February 2003 COM (2003) 75, in particular point 1.10. 
and trial in absentia have been suggested for further study. One of the reasons given by the Commission for suggesting this was that these topics have no priority. As is the custom with such papers, the Green Paper serves as a consultation paper in seeking to establish uniform procedural safeguards. Although the Commission intends to issue a framework decision on procedural safeguards in 2004, the critical response, from various governments as well, makes it completely uncertain when and how the proposals will be converted into legislation.

From the perspective of legal protection, it is disconcerting that measures such as the European arrest warrant will come into effect before an idea has been conceived on common minimum standards in the area of criminal proceedings. It is not anticipated that a consensus will soon be reached, or ever for that matter, and it is feared that, should a consensus be reached, legal protection will be levelled down. In view of the large differences in the national legal systems, all rooted in their own history, harmonisation within the EU of procedural safeguards for suspects and accused is a very complex matter, if not an unattainable goal. Rules of procedure of one system cannot be merely transplanted onto another. ${ }^{18}$ The cumbersome way in which the case law of the European Court of Human Rights (ECHR) is implemented in the national legal systems, is an indication that member states, in order to comply with the provisions of the European Convention, without exception opt for minimal-impact adjustments. Apparently, Italy, which scores highest with regard to violations of the 'reasonable time' requirement, feels that it is cheaper and easier to pay compensation to victims of such violations, who take the trouble to complain to the Strasbourg court, than to organise procedure in such a way that

18 See in this respect M.R. Damaska, 'Evidentiary Barriers to Conviction and Two Models of Criminal Procedure: A Comparative Study', 121 Pennsylvania Law Review 105 (1973) and M.R. Damaska, The Faces of Justice and State Authority, (Yale University Press, New Haven and London 1986). See for a more theoretical approach of the concept of harmonisation and concomitant problems and ssues: André Klip and Harmen van der Wilt (eds.), Harmonisation and harmonising measures in criminal law, (Royal Netherlands Academy of Arts and Sciences, Amsterdam 2002). 
accused can be tried within a reasonable period of time. There are many more such examples. The Netherlands has been condemned three times by the ECHR for the use of anonymous-witness statements. It is still arguable, however, whether the Dutch legislation governing threatened witnesses will be 'Strasbourg-proof' in all instances. ${ }^{19}$ Neither has the ruling by the ECHR that regular internal body searches of detainees at a Dutch High-Security prison in Vught, constitute inhuman treatment and therefore a violation of Article $3 \mathrm{ECHR},{ }^{20}$ resulted in an essential change of practice: the new regulation includes a provision that such body searches are only to take place randomly, but in practice searches occur systematically. ${ }^{21}$ Practice is tenacious and responds to conventional legal safeguards as a body does to alien organs. The system first tries to reject the organ and if it fails to do so, it accepts the organ by assimilation. ${ }^{22}$

There seem to be virtually no fundamental objections on the part of EU member states to mutual recognition of decisions of substantive and procedural law, inasmuch as they view it as a form of interstate cooperation, in which national autonomy with regard to criminal procedure remains intact: the member states are well aware of the advantages of cooperation to combat crime effectively. More resistance exists to the top-down determination by the EU institutions of actual procedural safeguards. The reactions of member states to the Green Paper on Procedural Safeguards reveal that many states have taken the position that there is no need to establish minimum standards for procedural safeguards protecting suspects and

19 ECHR 20 November 1989, Kostovski, A 166; ECHR 23 November 1997, Van Mechelen, Reports 1997-III and ECHR 14 February 2002, Visser, nr. 26668/95.

20 ECHR 4 February 2003, Lorsé and others, nr. 52750/99.

21 As a result, in urgency proceedings the Rotterdam District Court President ordered the State to perform random internal body searches only, President Rb. Den Haag 7 July 2003, KG 03/624, not yet published at the closure of this text.

22 As my colleague, Ties Prakken, put it so evocatively in her inaugural lecture: T. Prakken, Beginselen van een goede verdediging, (Deventer, Gouda Quint 1999), p. 6. 
accused to properly cooperate in judicial matters, since the standard has already been set by the European Court of Human Rights. ${ }^{23}$

\section{Conditions for Effective Legal Protection}

Legal protection is not automatically achieved by subscribing to the premises underlying the concept of 'fair trial'. These premises must be further defined if measures broadening the powers of public prosecutors, judicial bodies and investigative officers are to be counterweighted. In this respect, attempts in the Green Paper to arrive at a practical and efficient definition of procedural safeguards in all EU countries, are to be commended. However, the Commission places this initiative mainly in the context of enhancing mutual trust between the member states, so as to achieve cooperation in criminal matters. ${ }^{24}$ It has little regard for the friction between optimising safeguards for alleged offenders and smooth international cooperation. Furthermore, the Commission seems to overlook the considerable differences between the various systems of criminal procedure within the EU too readily. ${ }^{25}$

23 See the position of Germany, Ireland, Austria, the United Kingdom and the Netherlands on the Green Paper, prior to the public hearings by the Commission of 16 June 2003. So far (July 2003), only Finland and one future member state, the Czech Republic, have stated to be in favour of establishing procedural minimum standards.

24 See Green Paper Procedural Safeguards, § 1.7.

25 This is illustrated clearly in the earlier mentioned study: Analysis of the Green Paper on criminal-law protection of the financial interests of the Community and the establishment of a European Prosecutor, Study commissioned by the Committee on Budgets of the European Parliament by Anke Biehler, Dr Sabine Gleß, Nina Parra, Dr Helge Elisabeth Zeitler, (Freiburg/Br., Max Planck Institute of Foreign and International Criminal Law April, 2002). 


\section{A European Charter for Criminal Defence Lawyers?}

Until now, the Consultative Committee of the Bars and Law Societies of the European Community (CCBE) ${ }^{26}$ and a number of Bars and professional organisations of criminal defence hwyers have responded ad hoc to EU initiatives, but have not analysed these comprehensively from the perspective of the defence. In my introduction, I posed the question whether it was not time now for European criminal defence lawyers to reflect on common positions with regard to the conditions for an effective defence, their perception of their role and duties with regard to such defence, and whether this should not lead to a European Charter for Criminal Defence Lawyers. In my view, this question cannot but be answered in the affirmative. Developments at EU level, whether towards harmonisation or federalisation, are virtually unstoppable and definitively unilaterally aimed at the repressive side of criminal law. Procedural safeguards are rendered subservient to this aim. In the flight path of this, safeguards in the area of legal assistance, including professional privilege, which until recently were regarded as obvious, are under threat. I will return to this subject later. ${ }^{27}$ This has far-reaching consequences for legal protection and legal assistance. It is duty of the (Community) authorities to create the procedural preconditions for legal assistance to suspects and accused. Providing substance to legal assistance, on the other hand, is the responsibility of the European Bars and the organisations of criminal defence lawyers themselves. ${ }^{28}$ In view

26 Consultative Committee of the Bars and Law Societies of the European Community.

27 See below $\S 9$ under Confidential Communication.

28 See in this connection Recommendation Rec (2000) 21 of the Committee of Ministers to me mber states on the freedom of exercise of the profession of lawyer adopted on 25 October 2000 , where in 'Principle III- Role and duty of lawyers' is included: 'Bar associations or other lawyers' professional associations should draw up professional standards and codes of conduct and should ensure that, in defending the legitimate rights and interests or their clients, lawyers have a duty to act independently, diligently and fairly'; Conclus ions Council of Europe, The role and the responsibilities of the lawyer in a society in transition, 9-11 December 1997, Budapest (97) Concl., and the CCBE Declaration of Perugia on the Principles of Professional Conduct of the Bars and Law Societies of the European Community of 16 September 1977. 
of European (as well as global) ${ }^{29}$ developments, it is imperative that the profession, whose duty it is to defend the fundamental rights of suspects and accused, shows where it stands, how it sees its role and what facilities and guarantees it requires to practice their profession. These considerations, laid down in a Charter, may contribute both at European and domestic level towards taking a stand against the erosion of legal protection. Then there is the question of the contents of such a Charter. The answer to this question is more difficult and will require investigation and debate. I would like to provide an impetus to these discussions. I will limit myself to the right of suspects and accused to legal assistance as the procedural safeguard inextricably linked with the duty of the criminal defence lawyers.

\section{The Relation between the Right to Legal Assistance and Other Proce- dural Safeguards}

The right to legal assistance distinguishes itself from other procedural safeguards, such as the right to be informed of the charge against him, the right to silence, the privilege not to incriminate oneself, the right to examine witnesses - in short, the entire catalogue of procedural safeguards laid down in international treaties and national criminal procedures - in that the right to legal assistance is a precondition enabling the alleged offender to defend himself effectively and make use of the other safeguards afforded him.

In its Green Paper on Procedural Safeguards, the Commission views the right to legal assistance as 'the foundation of all other rights'. ${ }^{30}$ I prefer to use another

29 See the Agreement on extradition between the European Union and the United States of Amer-

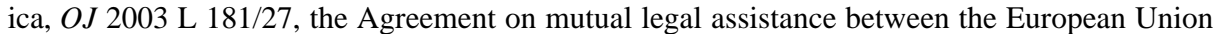
and the United States of America, OJ 2003 L 181/34 and Council Decision 2003/516/EC of 6 June 2003 concerning the signature of the Agreements between the European Union and the United States of America on extradition and mutual legal assistance in criminal matters, $O J$ 2003 L 181/25.

30 Green Paper Procedural Safeguards, § 2.5. 
phrasing, because all rights granted to the alleged offender, with the inclusion of the right to legal assistance, are founded on the principle that the alleged offender must be given a fair opportunity to defend himself. The right to defend oneself is one of the essential principles underlying the concept of 'fair trial'. This is underscored by the fact that Article 6 ECHR, which contains the right to defend oneself in criminal cases - in contradistinction to such other treaty provisions as Articles 5, 8 and $10 \mathrm{ECHR}-{ }^{31}$ does not provide for exceptions, such as measures necessary in a democratic society or in the interest of public security. The concept of 'fair trial', which includes the right to an effective defence, serves, after all, the interest of a democratic society. Although certain defence rights can be restricted, the right to defend oneself is absolute. ${ }^{32}$ In consequence, legal assistance is not the legal foundation of defence rights, but a prerequisite for the effective exercise of these rights. In this respect, it is important to be aware that Article 6 ECHR grants the alleged offender both the right to defend himself in person and the right to be assisted by counsel. These are not equivalent alternatives in the sense that the one type of defence can be substituted by the other. ${ }^{33}$ Both types of defence have their own pro-

31 The right to protection of personal liberty, privacy and freedom of expression.

32 This can be learned from ECHR case law in the area of the hearing of (anonymous) witnesses. In Kostovski the Court considered the following: 'Although the growth in organised crime doubtless demands the introduction of appropriate measures, the Government's submissions appear to the Court to lay insufficient weight on what the applicant's counsel described as 'the interest of everybody in a civilised society in a controllable and fair judicial procedure'. The right to fair judicial proceedings holds so prominent a place in a democratic society (see the Delcourt Judgment of 17 January 1970, A 11, p. 15, § 25) that it cannot be sacrificed to expediency. Powers of interrogation may be restricted, but in no instance to the degree that it makes conducting a defence impossible. The standard reasoning of the ECHR is: 'In addition, all the evidence must normally be produced at a public hearing in the presence of the accused, with a view to adversarial argument. There are exceptions to this principle, but they must not infringe the rights of the defence', see $\$ 51$ in Van Mechelen.

33 See M. Spaniol, Das Recht auf Verteidigersbeistand im Grundgezetz und in der Europäischen Menschenrechtskonvention, (Berlin, Duncker \& Humblot, 1990), pp. 63-64 and, for instance, ECHR 27 October 1998, H.N. v. Italy, nr. 18902/91; ECHR 12 Februari 1985, Colozza, A 89, § 27; ECHR 6 December 1988, Barbera and others, A 146, § 78; ECHR 21 September 1993, Kremzow, A 268-B, § 45 and ECHR 25 November 1997, Zana, Reports 1997-VII, § 67-72. The 
cedural function: the alleged offender contributes his personality and his knowledge of the facts and circumstances and counsel his legal knowledge and procedural experience. Paramount is that, in principle, the alleged offender has the right to defend himself in person and waive his right to be assisted by counsel. ${ }^{34}$

That the latter is not always seen as obvious can be learned from a number of cases tried before the Yugoslavia and Rwanda Tribunals. At issue in these cases was the question of whether the accused had a right to be assigned a defence lawyer of his own choosing, or whether, in the event the accused wished to conduct his own defence, or not conduct a defence at all, could be assigned a defence lawyer against his will. As regards the right to be defended by a defence lawyer of one's own choosing, the Rwanda Tribunal took the position that, although the choice of the alleged offender had to be taken into account, in principle, the right to choose one's own defence lawyer was not applicable in the event of assigned defence lawyers. ${ }^{35}$ In a case in which the accused had forbidden his lawyer to act on his behalf, because he did not recognise the Rwanda Tribunal and the lawyer in question had requested the Tribunal to discharge him, counsel's request was not honoured, be-

Human Rights Committee has expressed itself in the same vein in the HRC 2 April 1997, Michael and Brian Hill v. Spain, U.N. Doc. CCPR/C/59/526/1993, in which a complaint lodged against Spain was held to be in violation of Article 14, par. 3d CCPR, because, under Spanish law, Michael Hill, who did not want legal assistance, was not allowed to conduct his own defence.

34 See Article 6, par. 3 ECHR, which provides that everyone charged with a criminal offence has a right 'to defend himself in person or through legal assistance of his own choosing' and Article 14, par. 3 CCPR provides that such a person has a right 'to defend himself in person or through legal counsel of his own choosing'. According to the European Court of Human Rights this means that the person who has been charged with a criminal offence is entitled in principle to be present at this own trial and to participate in the proceedings. See, for instance,: ECHR $12 \mathrm{Fe} \mathrm{b}-$ ruary 1985, Colozza, A 89, § 27 and ECHR 16 December 1999, T. v. United Kingdom, nr. $24724 / 94, \S \S 88$ and 89 . Only in appellate and last-instance cases exceptions are possible if the case is limited to mere points of law and there are no disputed facts, or in cases in which no sentence is determined, see ECHR 10 February1996, Botten, Reports 1996-I, § 39.

35 Judgment of the Appeals Chamber 19 October 2000, Kambanda v. Prosecutor, Case No. ICTR 97-23-A and Judgment Appeals Chamber ICTR of 1 June 2001, Prosecutor v. Akayesu, Case No. ICTR-96-4. 
cause, according to the Tribunal, the accused only intended to obstruct the course of justice. ${ }^{36}$ The Yugoslavia Tribunal, on the other hand, seems to respect the choice of the alleged offender where counsel is assigned. ${ }^{37}$ In the case against Miloševic, the Yugoslavia Tribunal ruled that, although the right of the accused to defend himself in person was not absolute, assigned counsel could not be forced upon a competent and fit accused, who wished to conduct his own defence. In the case in question, the Yugoslavia Tribunal opted for the somewhat hybrid solution of designating amici curiae, who were to advise the Court in the interest of the accused's defence. ${ }^{38}$ Recently, however, the Yugoslavia Tribunal has assigned 'standby counsel' again st the will of an accused and determined that this 'standby counsel' was allowed to offer his comments at the request of the Tribunal and examine witnesses in the interest of the defence, if the accused, retaining his right to conduct his own defence, acted in an obstructive way. ${ }^{39}$

In my view, a decision by which counsel is assigned to an accused against the accused's will, constitutes a violation of the right to a fair trial. An accused cannot be forced to actively participate in the criminal proceedings instituted against him. ${ }^{40}$ If the accused chooses not to defend himself, for whatever reasons, this must be respected, in principle, inasmuch as it is a right, not an obligation, to defend oneself in person or to be legally assisted by counsel. Furthermore, counsel who does not have the confidence of the accused, cannot conduct a proper defence, because in

36 Decision (Request for Withdrawal of Defence Counsel), Barayagwizwa v. Prosecutor, Case No. ICTR-96-3-A, President ICTR, 7 July 2000.

37 Prosecutor v. Zoran Kupreškic and others, Decision on Defence Request for Assignment of Counsel ICTY, 10 March 1998, Case No. IT-95-16-T.

38 ICTY 4 April 2003, Reasons for Decision on the Prosecution Motion concerning Assignment of Counsel, Prosecutor v. Miloševic, Case No. IT-02-54 and ICTY 31 August 2001, Order Inviting Designation of Amicus Curiae, Prosecutor v. Miloševic, Case No. IT-02-54

39 ICTY 9 May 2003, Decision on Prosecution's Motion for Order Appointing Counsel to Assist Vojislav Seselj with his defence, Prosecutor v. Vojislav Seselj, Case No. IT-03-67-PT.

40 See ECHR 10 December 1982, Corigliano, A 57 in which the Court considers: '- it should be recalled that Article 6 does not require the person concerned actively to co-operate with the judicial authorities'. 
these instances the accused is not prepared to consult with this lawyer. In addition, lawyers face an impossible ethical dilemma: all codes of conduct prescribe that counsel cannot act for his client against that client's will. The reason for this is selfevident: clients must be able to make their own choices and should not be placed in a more disadvantageous position with than without counsel. To oblige counsel to render legal assistance against the will of his client is tantamount to force-feeding a hunger striker: it breaches his right of self-determination. ${ }^{41}$ The decisions by the Tribunals referred to earlier are more inspired by the interest of expediency than that of 'fair trial', in which the position taken by the accused must be respected. ${ }^{42}$

\section{Role and Duties of Criminal Defence Lawyers}

The core duty of defence counsel is to safeguard the freedom of the accused individual to defend his interests in criminal proceedings. Counsel's role here is not limited to influencing the trial in the interest of the accused, however. Counsel also has a duty to assist the accused, who suffers both mentally and socially as a result of being prosecuted. ${ }^{43}$ The key principles delineating the position of counsel are: partiality, independence and confidentiality. They are interconnected:

- Partiality is a necessary quality, because legal assistance is first and foremost a service that is rendered in conjunction with the individual freedom of the ac-

41 The tribunals refer extensively to the Croissant Case, ECHR 25 September 1992, A 237-B, in which the ECHR reasoned that it may be in the interests of justice that the accused is assisted by counsel, even against his wishes. As is clear from my proposition I do not agree with this. In my view, it is in the interests of justice that freedom of defence is respected. I do ask myself the question, incidentally, whether the ECHR would have disposed similarly in the case if Croissant had not been assisted by two lawyers of his own choosing as well, an aspect which was not taken into account by the Court.

42 See in a similar vain: Daniel D. Ntanda Nsereko, 'Ethical obligations of counsel in criminal proceedings: representing an unwilling client', 12 Criminal Law Forum (2001), pp. 487-507.

43 See in this respect EComHR 12 July 1984, Can, B 79. 
cused to determine, in principle, how he wishes to conduct his defence. Partia lity is also a necessary element of adversary proceedings and relevant to a balanced uncovering of the truth. Finally, partiality presupposes a certain degree of solidarity with the accused and is a condition for building a relationship of trust and confidentiality.

- Independence also serves several purposes and has several connotations. Counsel's attitude towards the authorities, the public and other parties involved in the proceedings, must be one of independence. This aspect serves to guarantee partiality: counsel must be guided by the interests of his client, even where these conflict with the interests of the authorities or third parties, and even where the pressures of public opinion are felt.

Independence also has a function in relation to the client. Because of his professional knowledge of criminal proceedings, the lawyer must serve as a professional sounding board for his client and guard him against adverse decisions. Clients only benefit from their lawyer's expertise if the latter approaches the case in a more detached way and makes a realistic assessment of the client's position and possible defences.

Furthermore, independence allows lawyers $\mathrm{b}$ work within certain constraints when acting for their client. They must not act contrary to the law nor abuse such privileges as unrestricted access to their client. This aspect of independence connects the defence of the party's interests to the principles of proportionality and subsidiarity. It also entails that such defence of interests may be conducted by lawful means only. This connotation of independence creates a friction, in that the client's interests may conflict with the interests of good practice. A reference is sometimes made to 'the interests of justice' in this context. ${ }^{44}$ Crucial here is what is meant by 'the interests of justice'; opinions are di-

44 See in this respect the Preamble to the Code of Conduct for lawyers in the European Union, as amended most recently on 6 December 2002, in which it is laid down that: 'A lawyer must serve the interests of justice as well as those whose rights and liberties he is trusted to assert and defend and his duty is not only to plead his client's cause but to be his adviser. A lawyer's func- 
vided. In some instances, the interests of justice are equalled to the interests of combating crime and the lawyer is expected to take these interests into account in defending his client. In my view, this conception of 'interests of justice' is incorrect. Good practice in criminal cases should first and foremost be linked to protecting the interests of human rights, within the limits of the law, against state power and the interests of combating crime. Although, on occasion, professional practice may be at odds with efficient prosecution, it is in no instance contrary to the interests of justice or public interest, because these interests imply that the accused is entitled to a proper and partial defence.

- Confidentiality, finally, is a conditio sine qua non, a pre-condition, without which the defence lawyer cannot function. The accused must be able to communicate with his counsel openly and freely, without having to fear that what he tells counsel in confidence will be disclosed or used against him. He must be able to rely on independent and knowledgeable advice, and counsel must place the accused's interests first. Confidential relationship also implies that both parties must be free to discontinue the relationship if an insurmountable breach of trust has taken place. If the client no longer has faith in his counsel, a basis for rendering legal assistance no longer exists and counsel will have to withdraw.

tion therefore lays on him a variety of legal and moral obligations (sometimes appearing to be in conflict with each other)'. See also the Introduction to the Gedragsregels 1992 of the Nederlandse Orde van Advocaten (1992 Code of Conduct of the Dutch Bar Association), which provides that the lawyer's primary duty is the defence of the client's interests entrusted to him, 'however, that he must exercise that duty in accordance with public interest in the proper practice of the profession, as a result of which it may be necessary that the interest of his client must give way.' In Common Law countries, such as England and Ireland, where the lawyer is at the same time an 'officer of the court', in the event of conflict it is assumed that the obligations towards the court, for instance in a case of misleading the court, must take precedence over the interests of the client. This premise must be seen in conjunction with the duties and role of the hwyer in the Anglo-Saxon adversary procedural system. See, for instance, P.J. Baker, 'Lawyers Duties to the Court', The Law Quarterly Review (1998), p. 103; Meredith Blake and Andrew Ashworth, 'Some Ethical Issues in Prosecuting and Defending Criminal Cases', Criminal Law Review (1998), pp. 16-34. 


\section{Guarantees for Proper Legal Assistance}

\section{Initial Moment}

Criminal procedure must contain a number of safeguards if legal assistance is to be effected. In the first place, the right to legal assistance must be defined and incorporated into the rules of criminal procedure. This also holds true for the moment at which the right to legal assistance becomes operative. The Green Paper on Procedural Safeguards departs from the premise that the right to legal assistance comes into operation upon arrest and that the alleged offender is entitled to legal assistance throughout the investigation and examination. This is a delicate issue in some of the EU jurisdictions, which exposes the fundamental differences between the tenets of Anglo-Saxon procedure and those of the inquisitorial continental systems most prominently. Whereas in Common Law countries the right to legal assistance during police interrogation is the rule, because the suspect or accused is not an object of investigation, but free to determine his position, this right does not exist in many continental countries, the Netherlands, Belgium and France among them. In inquisitorial systems, police interrogation is the stage that is most crucial to the alleged offender, because statements made by him during interrogation can be used in evidence. In this stage, the alleged offender needs to take vital decisions with regard to the position he will take in the proceedings, in particular with regard to his right to silence. This has far-reaching consequences for the remainder of the criminal proceedings instituted against him. The reason why alleged offenders are deprived of legal assistance during police interrogation is dictated by the fear that the presence of a defence lawyer will be an obstacle on the road to confession and therefore will negatively affect the uncovering of the truth. In inquisitorial systems, the right to legal assistance during preliminary proceedings is not a right in principle, therefore, but a right subject to the interests of the investigation. ECHR case law shows that alleged offenders must be given the opportunity in any case to consult a lawyer in the first stage of police interrogation, especially so where the alleged offender needs to take important decisions, which will affect the remainder 
of the preliminary proceedings. ${ }^{45}$ In Dougan, the ECHR considered, however, that the accused did not derive a right from Article 6 ECHR to have his lawyer present. ${ }^{46}$ It is remarkable that the European Court departs here from the recommendation put forward by the European Committee for the Prevention of Torture (CPT) and the Statutes of the international war tribunals. ${ }^{47}$ In view of the alleged offender's right to silence, which is recognised in all EU jurisdictions, including those of an inquisitorial nature, there seems to be no reason why the interests of the investigation is a legitimate argument to deprive the alleged offender of legal assistance during police interrogation. It is precisely at this stage that the alleged offender needs information, advice and support. The right to legal assistance during police interrogation should, therefore, be guaranteed in principle.

Furthermore, it is of relevance that, where the case exceeds national borders, the alleged offender must be granted legal assistance in both the country in which he is residing and the country in which the case is investigated or prosecuted. The Green Paper on Procedural Guarantees fails to address this issue. ${ }^{48}$

\section{Assigned Counsel}

One of the cornerstones of legal assistance is that the government provides such assistance if the alleged offender is unable to pay for it. A system of assignment exists in most EU member states. However, the weak link is the remuneration of the counsel assigned. Only assigned counsel in the UK and Ireland are properly remunerated. In the remaining EU member states, remuneration hardly covers the

45 See, for instance, ECHR 8 February 1996, Murray, Reports 1996-I; ECHR 2 May 2000, Condron, no. 35718/97; ECHR 6 June 2000, Magee, nr. 28135/95 and ECHR 6 June 2000, Averill, nr. 36408/97.

46 ECHR 14 December 1999, Dougan, no. 44738/98.

47 See Article 55, par. 2d Rome Statute of the International Criminal Court and Article 18 Statute of the International Criminal Tribunal for the Former Yugoslavia.

48 This is pointed out in the Stellungnahme der Strafverteidigervereinigungen und der Arbeitsgruppe eu-defence zum Greenpaper from the Commission Procedural Safeguards for Suspects and Defendants in Criminal Proceedings throughout the European Union of 24 May 2003, to be found on: <www.organisation.strafverteidigervereinigungen.org>. 
lawyer's overhead, or is so little that it actually boils down to pro bono assistance. This is not conducive to the quality of legal assistance. Where lawyers are obliged to render legal assistance by assignment in criminal cases - as if it were a professional duty which does not need to be properly rewarded - legal assistance is often passed on to inexperienced young lawyers or a minimal number of hours is spent working on such cases. ${ }^{49}$ The Green Paper on Procedural Safeguards deals with this aspect and raises the question of the extent to which member states can be obliged to pay assigned counsel a level of compensation that makes it attractive for lawyers to assist indigent suspects and accused. In view of the financial repercussions of decent remuneration, the response of the majority of member states to the Commission's question has been reserved. In its reaction to the Green Paper, the CCBE proposes that a study be conducted for each member state investigating the degree to which the assignment system results in effective legal assistance and whether remuneration is sufficient for qualified lawyers to participate in the system. ${ }^{50}$ I feel that such a study is of great importance, since a well-functioning assignment system will either make or break the effectiveness and quality of the defence. Finally, the alleged offender should be assigned counsel of his own choosing, if that lawyer is willing and able to take on the defence. In most member states, this is not the case and an indigent suspect or accused who depends on assigned legal assistance, is deprived of that choice.

49 In Van der Mussele v. Belgium, ECHR 23 November 1983, A 70, the Court has declared baseless a complaint by Van der Mussele on the grounds of violation of Article 4 ECHR (prohibition against forced labour), that as a trainee-lawyer he was obliged to render legal assistance to an alleged offender in a criminal case without remuneration, because, put briefly, providing pro bono assistance is part of the profession of lawyer.

50 CCBE Response to the Green Paper on Procedural safeguards for suspects and defendants in criminal proceedings throughout the European Union, 27 May 2003. See for the disconcerting situation in the countries which will shortly accede to the European Union: Access to Justice in Central and Eastern Europe, Comparative Report November 2002, presented at the European Forum on Access to Justice 5-7 December 2002 in Budapest, to be found on: <http://www.pili.org/library/access/country_reports.html>. 


\section{Procedural Powers}

Furthermore, a number of additional safeguards is needed relating to the manner in which counsel can exercise procedural powers in the name of the accused. This regards the substance of legal assistance. At issue here are such rights as the right to information; access to the case file; the right to be present at examinations, arraignments and court hearings; and to speak there; the right to examine witnesses; and the right to make or have made inquiries into the existence of disculpatory evidence. Counsel must have the same procedural powers as the accused. I intentionally use the word 'the same', not suggesting, therefore, that counsel should have more powers or powers different from those enjoyed by the accused. This would violate the premise that the alleged offender has the right to defend himself in person and is therefore primarily the one who must be able to wield his powers of defence, even when not assisted by a lawyer. ${ }^{51}$

A special problem with regard to the granting of procedural powers is counsel conducting a defence in the absence of the accused. This problem has manifested itself in particular in the Netherlands, Belgium and France. It is possible in these countries to convict an accused in absentia. Formerly, defence counsel was not allowed to speak in defence of the accused if the accused himself was not present. In Poitrimol, Van Geyseghem, Lala and Pelladoah, the ECHR held this practice to be contrary to Article 6 ECHR. ${ }^{52}$ The Netherlands has introduced a set of rules under which the accused may grant counsel a power of attorney to represent him. If this happens, the proceedings are regarded as adversary. This implies also that the terms within which an appeal may be lodged are shorter than those for in-absentia proceeding. In the latter, judgments must first be served before the term for appeal becomes operative. Another consequence is that decisions can be more readily en-

51 ECHR 18 March 1997, Foucher, Reports 1997-II.

52 France: ECHR 23 November 1993, Poitrimol, A 277-A; Netherlands: ECHR 22 September 1994, Pelladoah, A 297-B; ECHR 22 September 1994, Lala, 297-A; Belgium: ECHR 21 January 1999, Van Geyseghem, Reports 1999-I. 
forced ${ }^{53}$ In France, a Bill has been introduced, in which a similar construction is proposed, ${ }^{54}$ and in Belgium a similar practice exists on the basis of decided cases. There are fundamental objections to these regulations, since they depart from the fiction that the requirements of adversary proceedings are met if counsel is allowed to conduct a defence. This overlooks that it is the presence of the accused hat makes the proceedings adversary, counsel being no proper substitute for the accused. Another negative aspect of the power-of-attorney rule is that it dilutes the right of the accused to be present at his own trial. From recent research conducted in the Netherlands into the operation of the in absentia rule it has been learned that from time to time judges deny requests for an adjournment, made to exercise the right to be present, due to limited session capacity. It has also shown that more weight seems to be attached to efficiency than to the interests of a defence conducted in the presence of the accused. ${ }^{55}$

As a result of the power-of-attorney provision, defence lawyers may face a troublesome choice, especially if consultation with the client is impossible. In the course of the hearings, all kinds of unforeseen circumstances, not anticipated by counsel and his client, may emerge. The far-reaching consequences of adversary proceedings present the defence lawyer with a complex dilemma in the event he loses contact with his client after the power of attorney was conferred on him: if he does not disclose that he is representing his client under a power of attorney, he cannot conduct the defence; ${ }^{56}$ if he does declare that he is acting under a power of attorney, he may run up against situations about which no consultation took place with the client. The regulation does not seem to have been introduced to improve the quality

53 See for a description of the legislative history and criticism of the regulation: T. Spronken, Verdediging.Een onderzoek naar de normering van het optreden van advocaten in strafzaken, (Arnhem, Gouda Quint 2001), § 2.6.3-§ 2.6.5.

54 See Article 58 of the Bill of 9 April 2003, introduced by Raffarin and Perben. The Bill has already been adopted by the Assemblee and must now be debated in the Sénat.

55 See the report by W.E.C.A. Valkenburg, P.D van Hees and P.A.W. Verboort, Evaluatie verstekregeling in strafzaken, (Tilburg/'s-Gravenhage: Faculteit der Rechtsgeleerdheid/WODC 2002), to be found on: <www.wodc. $\mathrm{nl}$.

56 Netherlands Supreme Court, HR 23 April 2002, NJ 2002, 338. 
of the proceedings, but rather to facilitate the execution of judgments. As long as it remains possible to convict an accused in absentia, it does not seem to make sense to prohibit counsel from conducting a defence in the absence of his client, meaning without the fiction that the proceedings are of an adversary nature. This strengthens the adversary character of the proceedings as opposed to the situation in which counsel has no right whatsoever to act for his client in the event that his client is absent. Counsel must be able to conduct a defence without this having a negative impact on the accused's position. Attaching negative effects to the right to conduct a defence is, in my view, a violation of Article 6 ECHR. ${ }^{57}$

\section{Confidential Communication}

An essential condition for effective legal assistance is the right to confidential communication with the accused: the right to unrestricted access. This means that there must be guarantees that counsel is allowed to visit and speak with his client in confidence, without third parties being able to discover what is communicated. This also applies to written communication and telephone conversations. Access must be such that a defence can be prepared. ${ }^{58}$

A guarantee related to unrestricted access is that the defence lawyer enjoys professional privilege. He cannot be compelled to disclose what has come to his knowledge in the context of the defence. This means not only that defence lawyers cannot be forced to disclose confidential information in a witness capacity, but also that sufficient measures must be taken to prevent that confidential information co-

57 See in this context, ECHR 13 February 2001, Krombach v. France, Reports 2001-II, in which the possibility of lodging an appeal was made subject to the condition that the accused turn himself in. In connection with this the ECHR considered the following: ' $\$ 87$ On the other hand, there can be no question of an accused being obliged to surrender to custody in order to secure the right to be retried in conditions that comply with Article 6 of the Convention, for that would entail making the exercise of the right to a fair hearing conditional on the accused offering up his or her physical liberty as a form of guarantee. In the same vein: ECHR 16 May 2002, Karatas and Sari v. France, nr. 38396/97.

58 ECHR 12-03-2003, Öcalan v. Turkey, nr. 46221/99. 
comes to the knowledge of the judicial authorities through the application of such investigative methods as interception of telephone conversations. There are some disturbing developments in this area. In France, for instance, a Bill has been introduced which will make it possible for the judicial authorities to request the handing over of documents without the defence having the possibility of invoking lawyerclient privilege. ${ }^{59}$ As for the Netherlands, since the coming into effect of the Special Investigative Methods Act on 1 February $2000,{ }^{60}$ investigative methods, such as surveillance, interception of telephone conversations, direct eavesdropping or the use of informers and under-cover agents, can be deployed against lawyers, even if they are not suspected to be involved in a crime themselves. Thus, confidential information may come to the knowledge of the judicial authorities, without the lawyer being aware. Although data governed by lawyer-client privilege must be destroyed by the public prosecutor immediately upon use, in practice this obligation is not complied with as a rule. ${ }^{61}$

In view of these developments, protection of professional privilege must be better regulated. Powers of seizure should not extend to confidential data relating to privileged professional relationships. Confidential data must be separated from nonconfidential data by a judge together with an independent lawyer, for instance the dean of the local bar association. ${ }^{62}$ As regards the investigative powers referred to earlier, such as surveillance, interception and infiltration, there should be guarantees that these are not deployed against professionals, such as lawyers, who are bound to secrecy. It is absurd, for instance, that in the Netherlands, intercepting telephone conversations held over the telephone connection of a law firm, or placing eavesdropping equipment in a law firm, is allowed, whereas a search of the

59 See Article 28 of the Bill of 9 April 2003, introduced by Raffarin and Perben. The Bill has already been adopted by the Assemblee and must now be debated by the Sénat.

60 Act of 27 May 1999, Stb. 1999, 245.

61 See for a discussion of these issues T. Spronken, 'De privileges van de raadsman', in: T. Prakken and T. Spronken (eds.), Handboek verdediging, (Deventer, Kluwer 2003), Chapter 2, § 4.2.17.

62 ECHR 16 December 1992, Niemietz, A 251-B. 
offices of a lawyer can only take place with a judge present and is protected by all sorts of safeguards to avoid that confidentiality is breached. The obligation to destroy the information obtained upon use, an obligation imposed, of all things, on the public prosecutor after he has taken cognisance of the contents, cannot be regarded as sufficient protection of lawyer-client privilege. ${ }^{63}$

The destruction of privileged information, which comes to the knowledge of the judicial authorities as a result of investigative methods deployed against the alleged offender, needs regulation. The safeguards referred to earlier must be incorporated into legislation and should not be left to variable local or national customs. Regulation at EU level to protect lawyer-client privilege is called for, especially now that borders within the EU no longer constitute an impediment to the deployment of these investigative methods - methods with such a grave impact on privacy.

\section{Freedom of Defence}

Finally, freedom of defence must also be safeguarded in the sense that, in principle, defence lawyers may adduce all that is deemed conducive to the defence. Counsel must not be regarded as an extension of their (criminal) clients and rendering $\mathbf{k}$ gitimate legal assistance must not be turned into a criminal act. This seems selfevident, but practice presents a different picture. Recently, in both the Netherlands and Germany, lawyers were arrested, while rendering legal assistance. In the Netherlands, this happened when lawyers refused to leave their client, when he was threatened by unlawful extradition. As a result of being arrested, the lawyers were prevented from employing any means of redress for the benefit of their client and visits from other lawyers who wanted to assist them were denied. ${ }^{64}$ In Germany, a lawyer was arrested during a court hearing when he requested that the judge's remark that the defendant should have been released, but that he would not release him because of the tone of voice in which counsel had asked for his release, be en-

63 The same conclusion is drawn by the College Bescherming Persoonsgegevens in its report 'Onderzoek naar de waarborging van de vertrouwelijke communicatie van advocaten bij de interceptie van telecommunicatie' of 17 July 2003, to be found on <www.cbpweb.nl>.

64 T. Spronken, 'Arrestatie van advocaten Mullah Krekar', NbSr (2003), pp. 101-103. 
tered into the records. ${ }^{65}$ If judicial authorities find that lawyers exceed the limits of proper defence, they must follow the disciplinary course in stead of instituting criminal proceedings.

In this respect, I refer to a number of international regulations intended to protect lawyers against prosecution for activities which they undertake in the legitimate defence of their client and in conformity with their own code of conduct.

Among these are the UN Basic Principles on the Role of Lawyers, also referred to as the Havana Principles, which contain an obligation imposed on the authorities to safeguard the independence of lawyers. According to these Principles, lawyers must not fall victim to, nor be threatened with, criminal prosecution or other sanctions, if they their work in compliance with the standards and norms of conduct recognised by the profession. In particular, lawyers must mo be identified with their clients as a result of performing their professional duties and they must be exempted from criminal prosecution for expressions uttered in good faith before the court. ${ }^{66}$

65 'Strafverteidiger im Sitzungssaal in Ausübung senes Berufs verhaftet', Presseerklärung Strafverteidigervereinigung NRW, Essen 28 May 2003, <www.strafverteidigervereinigungen.org>.

66 UN Basic Principles on the Role of Lawyers adopted at the Eight Crime Congress, Havana 7 September 1990 and reaffirmed by General Assembly Resolution 45/121 on 14 December 1990. See also Recommendation REC (2000) 21 of the Committee of Ministers to member states on the freedom of exercise of the profession of lawyer, in which it is recommended to governments of the member states to take any measures to guarantee the freedom to practice the profession of lawyer and which includes the following: 'lawyers should not suffer or be threatened with any sanctions or pressure when acting in accordance with their professional standards'. Although the ECHR has ruled that freedom of expression may be restricted, in view of the special position of lawyers in the administration of justice (EHRM 20 May 1998, Schöpfer, Reports 1998II); in the case Nikula v. Finland (ECHR 21 March 2002, nr. 31611/96) the Court considers: 'Even so, the threat of an ex post facto review of counsel's criticism of another party to criminal proceedings - which the public prosecutor doubtless must be considered to be - is difficult to reconcile with defence counseP s duty to defend their clients' interests zealously. It follows that it should be primarily for counsel themselves, subject to supervision by the bench, to assess the relevance and usefulness of a defence argument without being influenced by the potential "chilling effect" of even a relatively light criminal sanction or an obligation to pay compensation for harm suffered or costs incurred'. 


\section{Obligations of Criminal Defence Lawyers}

Even where criminal procedure offers enough facilities and safeguards to enable effective legal assistance, they remain a dead letter if the defence lawyer does not avail himself of these in practice.

\section{Relationship of Trust and Free Choice of Counsel}

The lawyer needs to make an effort to bring about and preserve a relationship of trust with the alleged offender. He must handle this relationship with great care. Consultation with clients must take place and lawyers are not at liberty to conduct the defence in a manner contrary to the client's will.

If a difference of opinion between counsel and his client leads to a breach of such trust, counsel must withdraw, ensuring that the alleged offender suffers as little as possible as a result. Lawyers will have to respect the alleged offender's free choice of counsel and may not assist him against his will.

\section{Confidentiality}

It is very important that lawyers are obliged to keep confidential all that comes to their knowledge within the context of their rendering legal assistance. This goes beyond the mere communications of the alleged offender and comprises information that the lawyer receives from third parties in connection with the defence. Only if the task assigned to him requires that he make use of information received from third parties, is the lawyer at liberty to do so, providing that there is no objection by his client and that it conforms to good professional practice.

In this respect, the introduction of the obligation for lawyers to report unusual transactions is a serious blow for the right of citizens to legal advice. ${ }^{67}$ The duty

67 Directive 2001/97/EC of the European Parliament and of the Council of 4 December 2001 amending Council Directive 91/308/EEC on prevention of the use of the financial system for the purpose of money laundering, OJ $2001 \mathrm{~L} 344 / 76$. See for a discussion of the subject, T. Spronken, 'De Europese Witwasrichtlijn en de erosie van het verschoningsrecht', in: Iets Bij- 
jeopardises the role of lawyers in a state governed by the rule of law. Notwithstanding the fact that it is limited to advisory work (possibly) related to laundering activities, a psychological threshold has been crossed. The duty to report unusual transactions causes confusion and obfuscates the lawyer's role. Lawyers must not be deployed to detect criminal offences precisely because of their role.

\section{Prohibition against Defending Conflicting Interests}

To safeguard partiality, independence and professional secrecy, lawyers are not allowed to defend conflicting interests. This prohibition, which features in all codes of conduct, originated in private law. It is often defined as a prohibition against defending the interests of two or more parties involved. In criminal cases, this is mainly relevant where there is more than one alleged offender whose interests must be defended in the same case. These alleged offenders might have conflicting interests. The prohibition against defending conflicting interests purports to be more, however. Lawyers must not place themselves in a situation in which they are no longer free to exclusively concentrate on the interests of their client. ${ }^{68}$ This situation may arise as result of conflicting interests of several clients or a conflict of interests between the alleged offender and the lawyer himself. ${ }^{69}$

These are the principles, which, in my view, need to be incorporated into a European Charter for Criminal Defence Lawyers.

zonders: Liber Amicorum presented to Mischa Wladimiroff on the occasion of 30 years practice as a lawyer, Den Haag: SDU Uitgevers 2002.

68 See the General Principles for Ethics of Lawyers of the International Bar Association (IBA): 'Lawyers shall not place themselves in a position in which their clients' interests conflict with those of themselves, their partners or another client'.

69 This may be the case, for instance, if a lawyer is considered a suspect or accused in the same criminal case in which his client is an alleged offender. 


\section{Crossborder Legal Assistance}

The last question I wish to raise, is whether a European Charter for criminal defence lawyers could provide a solution for the problems with which lawyers are faced if they are involved in the defence of alleged offenders in a EU member state other than the one is which their practice is established. Lawyers from EU member states are allowed to act and establish themselves in member states other than their own. ${ }^{70}$ In either instance, when engaged in activities, for which the capacity of a lawyer is required and where the lawyer acts in the name of his client, he is obliged to work in conjunction with a lawyer of the host country. The operative principle is that the visiting lawyer observes the professional code applicable in the host country, while at the same time complying with his domestic code of conduct. Lawyers acting in a professional capacity in a host country may also be subject to the disciplinary law of the host country. ${ }^{71}$ The substance of the obligation to work with a lawyer of the host country was established in 1988 by the European Court of Justice in a case against the Federal Republic of Germany. ${ }^{72}$ The local lawyer is to render the necessary assistance to the visiting lawyer who acts under a legal system other than his own. The lawyers must establish among themselves how this collaboration is to take shape in conformity with their mandate and in observance of

70 This is regulated by Council Directive 77/249/EEC of 22 March 1977 to facilitate the effective exercise by lawyers of freedom to provide services, JO 1977 L 78/17; Council Directive 89/48/EEC of 21 December 1988 on a general system for the recognition of higher-education diplomas awarded on completion of professional education and training of at least three years' duration, OJ 1989 L 19/16 and Directive 98/5/EC of the European Parliament and of the Council of 16 February 1998 to facilitate practice of the profession of lawyer on a permanent basis in a Member State other than that in which the qualification was obtained, OJ $1998 \mathrm{~L} \mathrm{77/36.}$

71 The details of the regulation are more complex than indicated here, and may vary per state, because Article 7, par. 2 of Directive 77/249/EG confers discretionary powers on the member states. For instance in the Netherlands, in relation to the applicability of professional rules a distinction is made according to the type of work performed and whether the lawyer is registered under his own title. See for a structured overview of the Dutch situation, F. Orie, 'Het Nederlandse tuchtrecht', in: Recht op tuchtrecht, 50 jaar Hof van Discipline, (2003), pp. 196-207. ECJ 25 February 1988, Case 427/85, NJ 1990, 22. 
the operative professional codes. Member states may set rules for such collaboration. However, these cannot provide that solely the national lawyer is to represent the alleged offender or that a lawyer from another member state can only appear in court in the company of a local lawyer. Nor can unreasonable rules be set for evidence of such collaboration, in that it has to be demonstrated for each single act. As regards visits to detained clients, it cannot be required that the visiting lawyer may only visit the client in the company of a local lawyer or that correspondence with a detained client must be conducted through the local lawyer.

In a nutshell, this is the regulation governing lawyers acting outside their own country. It does not offer a solution for the problem of coping with conflicting professional codes in the event that legal assistance is rendered in both the home and host country.

How, for instance, is a Dutch lawyer, who is not an officer of the court, as is his English counterpart, to deal with the prohibition, applicable in England, against misleading the court, when his Dutch client, who had confessed his guilt to his hwyer when still in the Netherlands, upon having been extradited to England, wishes to deny the charge before the English court? The codes of conduct for English solicitors and barristers prohibit in such instances pursuance of a defensive strategy that does not conform with the admission of guilt. ${ }^{73}$ Should a Dutch lawyer, wishing to assist his client before an English court, withhold the confession from his English counterpart?

In Belgium, lawyers are prohibited from having contact with any witnesses prior to the case being tried before the court. How then to collaborate with a colleague from

73 The Code of Conduct of the Bar of England and Wales provides as regards admissions of guilt: 'It follows that the mere fact that a person charged with a crime has confessed to his counsel that he did commit the offence charged is no bar to that barrister appearing or continuing to appear in his defence, nor indeed dows such a confession release the barrister from his imperative duty to do all that he honourably can for his client.[...] Such a confession, however, imposes very strict limitations on the conduct of the defence. A barrister must not assert as true that which he knows to be false. He must not connive at, much less attempt to substantiate, a fraud [...] He must not set up an affirmative case inconsistent with the confession made to him'. 
another member state where such prohibition does not exist, who had extensive telephone conversations with the witness in order to prepare himself for witness examination in Belgium?

If both investigation and trial of a criminal case take place in one member state only, ordinarily the professional rules of that member state will apply to the visiting lawyer. This will not, however, provide solace where legal assistance needs to be provided in various countries with different professional codes. There are no easy solutions for such situations, however. Professional rules and national criminal procedures are interconnected. No solution may be expected, therefore, from the harmonisation of codes of conduct recently proclaimed by the European Commission, ${ }^{74}$ so long as each member state preserves its own stamp on criminal law. A Charter will not and is not intended to resolve this problem.

In spite of this, accepting and explicitating common premises may prompt critical examination one's own code of conduct. Such codes are often founded on tradition. As a result, whether and how it contributes towards a proper defence in criminal cases is not questioned. Furthermore, codes of conduct may be tested against the principles underlying effective defence found in the European Convention and developed by the Strasbourg court. I would like, therefore, to conclude with some examples: I pose myself the question whether the prohibition for Belgian lawyers to have any contact with witnesses before trial is compatible with the principle of equality of arms, while the police and the public prosecutor's office do have these powers. And how do we square the fact that a lawyer entrusted with a client's confession is no longer allowed to function properly as a defence lawyer in England, for a client who subsequently declares his innocence before the English court, with

74 Press release from the European Commission on the Internal Market Strategy 2003-2006, of 7 May 2003 which refers to a proposal from the Commission for a Directive on services before the end of 2003. In this context the European Commission is of the opinion that there is a need for an approximisation - or harmonisation if necessary - of professional/deontological rules at European level. 
the freedom of the alleged offender to determine and conduct his own defence strategy, or, as the case may be, with the prohibition against self-incrimination?

Having arrived at the end of this inaugural lecture, I am aware that I have probably raised more questions than provided answers. Much investigative work remains to be done. I hope to have conveyed at least this much to you today: that combating crime must be inextricably linked with proper legal protection, if we are to reach a 'place of greater safety'. There is after all nothing more unsafe than an administration against which there is no defence. 